\title{
Current and Future Prospects for Anticoagulant Therapy: Inhibitors of Factor $\mathrm{Xa}$ and Factor IIa
}

\author{
Job Harenberg, M.D., ${ }^{1}$ and Martin Wehling, M.D. ${ }^{1}$
}

\section{ABSTRACT}

Indirect systemic and direct oral factor $\mathrm{Xa}$ and direct oral factor IIa inhibitors with improved pharmacologic profiles compared with heparins and vitamin $\mathrm{K}$ antagonists are currently in clinical development. This overview focuses on the indirect antithrombin dependent pentasaccharide derivatives of idraparinux and on the most advanced oral direct inhibitors to factor Xa (rivaroxaban and apixaban) and IIa (dabigatran). Specifically, the results of dose-finding studies for the prevention of venous thromboembolism after elective orthopedic surgery, the results of dose-finding studies for treatment of acute venous thromboembolism including prolonged prophylaxis of recurrent events, and the designs of ongoing clinical trials are reviewed.

KEYWORDS: Thromboembolism, factor Xa inhibitor, factor Ila inhibitor, anticoagulants, clinical trial

Currently available options for anticoagulation include treatment with unfractionated heparin (UFH), low-molecular-weight heparin (LMWH), vitamin $\mathrm{K}$ antagonists (VKAs), and, more recently, the synthetic pentasaccharide fondaparinux. Although these drugs have proved effective in treating and reducing the risk of thromboembolic disease, they are associated with significant drawbacks that limit their use and acceptability in the clinical setting. UFH, LMWH, and fondaparinux are administered parenterally; thus, they are inconvenient for long-term use and require dose adjustment according to the therapeutic range, either using the activated partial thromboplastin time (aPTT) or chromogenic assays, particularly in renal impairment, and they may also require the control of platelet counts. At present, VKAs are the only available oral anticoagu- lants; however, their slow onset and offset of action, narrow therapeutic window, genetic variations of metabolism, and food and drug interactions necessitate monitoring and dose adjustment to reach the therapeutic range of the international normalized ratio (INR) of 2 to 3 (Table 1). ${ }^{1}$ As a result, VKAs are difficult to manage in daily practice and in clinical studies. Thus, there is a real, as yet unmet, clinical need for novel oral anticoagulants with rapid onset of action and devoid of the drawbacks of conventional anticoagulants. ${ }^{2,3}$ The pharmacologic and clinical consequences of their desired characteristics are outlined in Table 2.

The development of new anticoagulants has therefore focused on synthetic, small-molecular-weight molecules to avoid the side effects or monitoring of conventional anticoagulants. The small synthetic
${ }^{1}$ Clinical Pharmacology Mannheim, Vascular Pharmacotherapy, Faculty of Medicine, University of Heidelberg, Mannheim, Germany. Address for correspondence and reprint requests: Job Harenberg, MD, Clinical Pharmacology Mannheim, Vascular Pharmacotherapy, Faculty of Medicine, University of Heidelberg, Theodor Kutzer Ufer 1-3, D-68167 Mannheim, Germany (e-mail: job.harenberg@ med.ma.uni-heidelberg.de).
Hot Topics II: An Editorial Collection of Current Issues and Controversies in Thrombosis and Hemostasis; Guest Editor, Emmanuel J. Favaloro, Ph.D., M.A.I.M.S.

Semin Thromb Hemost 2008;34:39-57. Copyright (C) 2008 by Thieme Medical Publishers, Inc., 333 Seventh Avenue, New York, NY 10001, USA. Tel: +1(212) 584-4662.

DOI 10.1055/s-2008-1066023. ISSN 0094-6176. 
Table 1 Pharmacologic Characteristics of Anticoagulants

\begin{tabular}{|c|c|c|c|c|c|c|}
\hline Active Drug & Target & Dosing & $\begin{array}{l}\text { Coagulation } \\
\text { Monitoring }\end{array}$ & Half-Life (h) & $\begin{array}{l}\text { Renal } \\
\text { Clearance } \\
(\%)\end{array}$ & Interactions \\
\hline Warfarin & $\begin{array}{l}\text { Vitamin } \mathrm{K} \text { epoxide } \\
\text { reductase }\end{array}$ & $\begin{array}{l}\text { INR-adjusted, } \\
\text { once daily }\end{array}$ & $\begin{array}{l}\text { INR 2-3 } \\
\text { or 2-4 }\end{array}$ & 40 & 0 & $\begin{array}{l}\text { CYP2Cg VCOR1 } \\
\text { Multiple others }\end{array}$ \\
\hline LMWH & $\begin{array}{l}\text { FXa, other coagulation } \\
\text { factors and proteins }\end{array}$ & Once or daily & No & $4-7$ & $\begin{array}{c}\text { Estimated } \\
40-70\end{array}$ & No relevant known \\
\hline $\begin{array}{l}\text { Idraparinux, } \\
\text { biotin-idraparinux }\end{array}$ & FXa & $\begin{array}{l}\text { Once per } \\
\text { week s.c. }\end{array}$ & No & $\begin{array}{l}7 \mathrm{~d} \text { (1 dose) to } \\
60 \mathrm{~d}(6 \mathrm{mo})\end{array}$ & $\begin{array}{l}\text { Estimated } \\
40-70\end{array}$ & No relevant known \\
\hline $\begin{array}{l}\text { Oral direct } \\
\text { FXa inhibitors }\end{array}$ & $\mathrm{FXa}$ & $\begin{array}{l}\text { Once or } \\
\text { twice daily }\end{array}$ & No & $9-14$ & $25-40$ & CYP3A4 inhibitors* \\
\hline $\begin{array}{l}\text { Oral direct } \\
\text { Flla inhibitors }\end{array}$ & Thrombin & Twice daily & No & 7 to 14 & 80 & Proton pump inhibitors ${ }^{\dagger}$ \\
\hline
\end{tabular}

*Includes ketoconazole, macrolides (e.g., clarithromycin), and protease inhibitors (e.g., atanazavir).

† Moderately reduces absorption.

s.c., subcutaneous.

molecules therefore target only one coagulation factor with high specificity. ${ }^{4}$ Small synthetic molecules directed toward factor (F) Xa and FIIa (thrombin) can neutralize their respective targets whether or not the targets are clot-bound or prothrombinase-bound, a distinct advantage over the indirect inhibitors that require antithrombin to mediate their effect. ${ }^{5,6}$ An overview of the mechanism of action of the direct FXa and FII inhibitors is given in Table 3. The target enzymes of the anticoagulants in this overview are shown in Fig. 1.

The current overview focuses on the indirect antithrombin dependent pentasaccharide derivatives of idraparinux and on the oral direct FXa and thrombin inhibitors in clinical development. The overview specifically describes the results of dose-finding studies in postoperative care, the results of dose-finding studies in the treatment of acute venous thromboembolism (VTE) including prolonged prophylaxis of recurrent events, and describes the designs of ongoing clinical trials.

\section{IDRAPARINUX}

Idraparinux is a hypermethylated derivative of fondaparinux that binds antithrombin with such high affinity that it assumes a plasma half-life of 80 hours, similar to that of antithrombin. ${ }^{7}$ It has linear pharmacokinetics, low interindividual and intraindividual variability, and may not require monitoring of anticoagulant intensity. ${ }^{8}$ Consequently, idraparinux can be given subcutaneously on a once-weekly basis. Neither fondaparinux nor idraparinux interact with protamine sulfate, the antidote for heparin. Thus, if uncontrolled bleeding occurs, a procoagulant, such as recombinant factor VIIa, may be beneficial. ${ }^{9}$ Because of its long half-life, idraparinux has not been investigated in postoperative medicine.

Idraparinux was evaluated in a phase II dosefinding trial of 659 patients with proximal deep-vein thrombosis (DVT). Patients were randomly assigned to warfarin or to one of four doses of once-weekly subcutaneous idraparinux after 5 to 7 days of initial therapy with enoxaparin. The primary efficacy outcome was the composite of change in thrombotic burden, as assessed by ultrasonography and perfusion lung scanning at baseline and week $12 \pm 1$ and by clinical thromboembolic events. This outcome was classified as normalization, no relevant change, or deterioration. Other outcomes were major and other clinically relevant bleeding episodes. The rates of normalization and deterioration were similar in all groups

Table 2 Some Desired Characteristics and Consequences for New Anticoagulants

\begin{tabular}{|c|c|}
\hline Characteristics & Consequences \\
\hline Rapid onset of action & $\begin{array}{l}\text { No need for overlap with parenteral anticoagulants; simplified management in } \\
\text { case of a hemorrhagic event or need for an intervention and minimizes } \\
\text { need for an antidote }\end{array}$ \\
\hline Predictable pharmacokinetics & Simplified dosing regimens \\
\hline Predictable anticoagulant response & Fixed dose, no need for coagulation monitoring and dose adjustment \\
\hline No CYP2C9 or VCOR1 metabolism & Lack of food interactions, few if any drug interactions \\
\hline Availability of a safe antidote & Provides rapid reversal in case of a hemorrhagic event or need for an intervention \\
\hline No off-target effects, such as hepatoxicity & No need for monitoring \\
\hline Reasonable cost & Improved access, favors use for new indications \\
\hline
\end{tabular}


Table 3 Comparison of Indirect and Direct Factor Xa Inhibitors

\begin{tabular}{lll}
\hline & Indirect & Direct \\
\hline Inhibitory & AT dependent; & Non-AT dependent; \\
mechanism & catalytic & stoichiometric \\
Drug target & Free FXa & Free and bound FXa \\
Binding & Reversible & Reversible \\
\hline
\end{tabular}

AT, antithrombin.

$(p=0.4)$ and did not differ from the warfarin group. Additional analyses showed that 7 of 40 (18\%) assessable patients with active cancer had deterioration versus 39 of $574(7 \%)$ patients without active cancer. Similarly, 16 of $129(12 \%)$ assessable patients with a history of previous VTE had a deterioration versus 30 of 485 (6\%) patients without such a history. Gender, age, creatinine clearance, body weight, and pharmacokinetic parameters were not associated with differences in the frequency of deterioration.

There was a clear dose-response for major bleeding among patients treated with idraparinux $(p=0.003)$. Patients receiving $2.5 \mathrm{mg}$ idraparinux had less bleeding than did warfarin recipients $(p=0.03)$. Two patients, both in the $5 \mathrm{mg}$ idraparinux group, had a fatal hemorrhage (intracranial and gastrointestinal) during the study period. Among patients treated with idraparinux, there was a statistically significant dose-response relationship for major bleeds $(p=0.003)$ and for major and other clinically relevant bleeds $(p=0.001)$. The incidence of major hemorrhages in the $10 \mathrm{mg}$ idraparinux group was significantly higher than that in the warfarin group $(p=0.010){ }^{10}$

Phase III trials were conducted using $2.5 \mathrm{mg}$ idraparinux once weekly subcutaneously in patients without renal impairment and at a lower dose in patients with renal impairment. Two randomized, open-label noninferiority trials were conducted in patients with DVT and pulmonary embolism (PE) to compare the efficacy and safety of idraparinux versus standard therapy.
Patients who were assigned to the idraparinux group received a once-weekly subcutaneous dose of $2.5 \mathrm{mg}$. For patients with a creatinine clearance of less than $30 \mathrm{~mL} / \mathrm{min}$, the second and subsequent doses were $1.5 \mathrm{mg}$. Patients who were assigned to receive standard therapy received tinzaparin, enoxaparin, or intravenous heparin, followed by warfarin or acenocoumarol (INR 2.0 to 3.0). The primary efficacy outcome was symptomatic recurrent venous thromboembolism, defined as objectively documented recurrent PE, DVT, or death attributed to PE.

For the DVT study, 1452 patients were randomly assigned to idraparinux and 1452 to the standard therapy. The incidence of recurrent venous thromboembolism at day 92 was $2.9 \%$ in the idraparinux group and $3.0 \%$ in the standard therapy group. The treatment was noninferior to the standard therapy $(p<0.001)$. Between months 4 and 6 , four additional events occurred in each treatment group. The incidence of clinically relevant bleeding at day 92 was $4.5 \%$ in the idraparinux group and $7.0 \%$ in the standard therapy group $(p=0.004)$. After 6 months, the incidence of clinically relevant bleeding was $8.3 \%$ in the idraparinux group and $8.1 \%$ in the standard therapy group $(p=0.85)$. The rates of major bleeding were $0.8 \%$ and $1.2 \%$, respectively, at 3 months $(p=0.35)$ and $1.9 \%$ and $1.5 \%$ at 6 months $(p=0.50)$. The rate of death at 3 months was $2.3 \%$ in the idraparinux group and $2.0 \%$ in the standard therapy group $(p=0.61)$. The death rate after 6 months was $4.9 \%$ in the idraparinux group compared with $3.9 \%$ in the standard therapy group $(p=0.25)$.

In the PE study, the incidence of recurrent VTE was $3.4 \%$ in the idraparinux group and $1.6 \%$ in the standard therapy group. The noninferiority criterion was not met $(p=0.59)$. Between months 4 and 6 , five additional events occurred in the idraparinux group versus four events in the standard therapy group. The results did not meet the noninferiority criterion. The incidence of clinically relevant bleeding at 3 months was $5.8 \%$ in the idraparinux group and $8.2 \%$ in the standard therapy

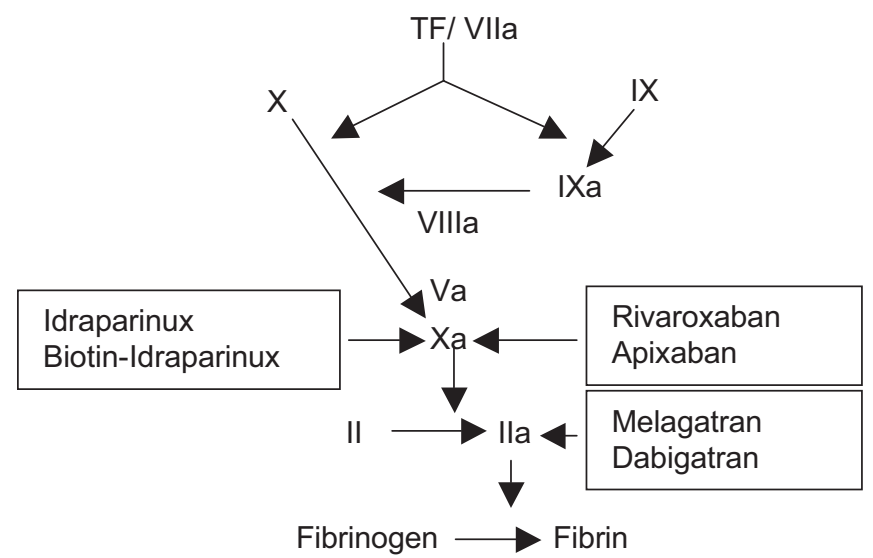

Figure 1 Targets of new oral anticoagulant drugs in the current overview. TF, time factor. 
group. At 6 months, these rates were $7.7 \%$ and $9.7 \%$, respectively. The rates of major bleeding were $1.1 \%$ and $2.1 \%$ at month 3 and $1.4 \%$ and $2.8 \%$ at month 6 . The death rates were $5.1 \%$ in the idraparinux group and $2.9 \%$ in the standard therapy group (month $3, p=0.006$ ). At 6 months, the death rate was $6.4 \%$ in the idraparinux group and $4.4 \%$ in the standard therapy group $(p=0.04)$.

It should be noted that in the PE study, the rate of recurrence of thromboembolism in the standard therapy group was lower than anticipated. In most of the contemporary studies, the recurrence rate has been 4 to $5 \%$ in the first 3 months, with recurrent $\mathrm{PE}$ accounting for about two thirds of events. In the PE study, the recurrence rate in the standard therapy group was only $1.6 \%$ at 3 months, and recurrences were PE in less than half of the patients $(44 \%)$, whereas the observed rates in the idraparinux group were consistent with those in previous studies. The excess of deaths from PE reinforces concern about the decreased efficacy of idraparinux in patients with $\mathrm{PE}$ in this setting. ${ }^{11}$

The prolonged prophylaxis of VTE using idraparinux has been investigated in the van Gogh Extension trial. Patients with confirmed, symptomatic DVT or PE who had been treated for 6 months with acenocoumarol or warfarin (either in previous van Gogh studies or outside these studies) or idraparinux (in van Gogh studies) were randomized to a once-weekly $2.5 \mathrm{mg}$ idraparinux or placebo. The primary efficacy outcome was the incidence of symptomatic recurrence of VTE, defined as objectively documented recurrent PE, DVT, or death attributed to $\mathrm{PE}$.

During the 6 months of randomly assigned treatment, 6 of 594 (1.0\%) patients in the idraparinux group and 23 of $621(3.7 \%)$ patients in the placebo group had symptomatic, objectively confirmed VTE. The reduction in the relative risk with idraparinux was $72.7 \%$ $(p=0.002)$. Major bleeding occurred in 11 of 594 (1.9\%) patients in the idraparinux group and in none of the 621 patients in the placebo group $(p<0.001)$. A higher incidence of major bleeding was observed in patients who had received idraparinux before randomization than in those who had received a VKA (3.1\% vs. $0.9 \% ; p=0.06)$. Three bleeding episodes in the idraparinux group were fatal intracranial hemorrhages and occurred in patients who had received idraparinux before entry into the trial.

During the observation period after the end of the additional 6 months of thromboprophylaxis, 7 (1.2\%) patients in the idraparinux group and 13 (2.1\%) patients in the placebo group had recurrent VTE $(p=0.21)$. It is noteworthy that events started to reoccur at 3 months in the placebo group when the patients had received the last injection of idraparinux 9 months ago. Major bleeding after discontinuation of the study drug occurred in $5(0.8 \%)$ patients in the idraparinux group and in none of the placebo group $(p=0.02)$. The episodes of bleeding, none of which were fatal, occurred from 1 to 20 weeks after the discontinuation of a study drug. During the entire period of observation, a major hemorrhagic episode occurred in 16 patients in the idraparinux group and in none of the patients in the placebo group $(p<0.001)$.

No major bleeding was observed in the placebo group, including patients who initially had received idraparinux, whereas in the idraparinux group, the incidence was $1.9 \%$. Of the 11 patients in the idraparinux group who had a major hemorrhage, eight had previously received idraparinux, and three had received a VKA. After completion of the extended idraparinux treatment, there were another five episodes of major bleeding in the idraparinux group. These observations suggest a prolonged risk of hemorrhage in patients treated with idraparinux for more than 6 months. The clinical benefit of such treatment remains to be confirmed because of bleeding complications during prolonged therapy with idraparinux. ${ }^{12}$

The pharmacodynamics of idraparinux was analyzed in 23 patients after termination of a 6- or 12-month therapy period for prevention of recurrent VTE at one center in the van Gogh trials. Of those, 18 patients were treated for 6 months and 5 patients for 12 months. FXa-specific S2222 chromogenic substrate $(\alpha \mathrm{Xa})$ assay, Heptest, prothrombin-induced clotting time $(\mathrm{PiCT})$, activated partial thromboplastin time (aPTT), and prothrombin time (PT) were determined in 3-month intervals for up to 15 months. Pharmacokinetic analysis of the $\alpha \mathrm{Xa}$ assay and Heptest derived elimination half-lives $\left(\mathrm{t}_{1 / 2}\right)$ of 60 days and 107 days $(p<0.0001)$, respectively. The detailed pharmacodynamic parameters are given in Table 4 . PiCT was prolonged for a period of 9 months. Coagulation times of aPTT and PT were not influenced. The $t_{1 / 2}$ was independent from creatinine clearance and the patient's body weight. The data support reports of a non-ionic binding of idraparinux to antithrombin and other proteins. $^{13}$

The long half-life of idraparinux may influence the incidence of recurrent VTE after termination of therapy in the van Gogh studies. For patients randomized to idraparinux in the van Gogh DVT or PE study followed by randomization to placebo for 6 months in the van Gogh Extension study, VTE reoccurred in only $\sim 1 \%$ of patients within 6 months. The prolonged circulation of idraparinux (elimination half-life time of 60 days) may have protected these patients from recurrent VTE in the van Gogh Extension trial. ${ }^{13}$

Approximately 4 to 5 half-life times are required to achieve a steady state of a drug. An elimination halflife of 60 days amounts to 240 to 300 days to reach steady-state conditions. The higher maximal concentration $\left(\mathrm{C}_{\max }\right)$ values of patients treated for 12 months 
Table 4 Pharmacodynamic Parameters of the Chromogenic Anti-FXa Activity and Heptest after Termination of 6 or 12 Months Therapy with Idraparinux

\begin{tabular}{|c|c|c|c|c|c|c|}
\hline & $t_{1 / 2}(d)$ & $\mathrm{C}_{\max }(\mu \mathrm{g} / \mathrm{mL})$ & $\begin{array}{l}\text { AUC inf obs } \\
\left(\mu \mathrm{g} \mathrm{mL}^{-1} \mathrm{~d}^{-1}\right)\end{array}$ & Vol diss (L) & $\begin{array}{l}\text { Clearance } \\
\text { (mL/min) }\end{array}$ & MRT (d) \\
\hline \multicolumn{7}{|c|}{ Part 1: 6-month (mean + SD) } \\
\hline S2222 & $60 \pm 14$ & $0.30 \pm 0.12$ & $34 \pm 15$ & $7.4 \pm 3.6$ & $0.09 \pm 0.06$ & $75 \pm 31$ \\
\hline Heptest & $107 \pm 34$ & $0.39 \pm 0.15$ & $51 \pm 27$ & $8.5 \pm 4.5$ & $0.06 \pm 0.03$ & $121 \pm 49$ \\
\hline$p$ value & $<0.0001$ & 0.0016 & 0.0002 & 0.1336 & $<0.0001$ & 0.0001 \\
\hline \multicolumn{7}{|c|}{ Part 2: S2222 (mean \pm SD) } \\
\hline 6 months & $59 \pm 15$ & $0.26 \pm 0.10$ & $29 \pm 14$ & $8.5 \pm 3.5$ & $0.11 \pm 0.06$ & $74 \pm 34$ \\
\hline 12 months & $62 \pm 11$ & $0.44 \pm 0.08$ & $48 \pm 8$ & $4.1 \pm 0.6$ & $0.05 \pm 0.02$ & $76 \pm 24$ \\
\hline$p$ value & 0.7236 & 0.0013 & 0.0114 & 0.0052 & 0.0088 & 0.9304 \\
\hline \multicolumn{7}{|c|}{ Part 3: Heptest (mean + SD) } \\
\hline 6 months & $108 \pm 39$ & $0.35 \pm 0.13$ & $43 \pm 22$ & $9.8 \pm 4.5$ & $0.07 \pm 0.03$ & $119 \pm 55$ \\
\hline 12 months & $106 \pm 19$ & $0.54 \pm 0.11$ & $77 \pm 27$ & $4.7 \pm 1.3$ & $0.03 \pm 0.01$ & $129 \pm 30$ \\
\hline$p$ value & 0.9293 & 0.0085 & 0.012 & 0.0145 & 0.0145 & 0.9304 \\
\hline
\end{tabular}

$\mathrm{t}_{1 / 2}$, elimination half life; $\mathrm{C}_{\max }$, maximal concentration; AUC inf obs, area under the curve, infinity observation calculated; Vol diss, volume of distribution; MRT, mean residence time.

compared with those treated for 6 months indicate that the steady-state conditions of idraparinux are not yet reached after 6 months of therapy, if the anticoagulant is given once weekly subcutaneously. The higher concentration of idraparinux after 12 months of therapy may explain the higher bleeding rate of patients treated for 12 months compared with 6 months. The antagonism of the anticoagulant activity of the new biotinylated idraparinux by avidin may offer an option for further improvement of anticoagulant treatment. ${ }^{14}$

Patients $(n=23)$ in the van Gogh trials were also followed-up over 24 months at one center for bleeding events, recurrent VTE, and other severe events. During the main study period within the van Gogh trials, two major bleeding complications occurred in patients randomized to warfarin (days 70 and 186). During the follow-up period, two patients initially randomized to idraparinux suffered from major bleeding events (days 65 and 140 during follow-up). Bleeding was related to an additional therapy of warfarin or LMWH, which was indicated in these patients. The very long half-life of idraparinux was unknown at that time. Thereafter, the long elimination time of idraparinux was taken into consideration. Two patients who needed continuation of anticoagulation after termination of idraparinux warfarin or LMWH were started at a plasma concentration of $0.1 \mu \mathrm{g} / \mathrm{mL}$ idraparinux or below. During follow-up, VTE occurred in two patients each initially randomized to warfarin (days 58 and 406) and idraparinux (days 266 and 381), respectively. The concentrations of idraparinux were $<0.01$ $\mu \mathrm{g} / \mathrm{mL}$ in both patients. The data show that the very long half-life of idraparinux may lead to serious bleeding complications if anticoagulation is given on top of the circulating compound within 3 or 4 months after termination of therapy. Recurrent VTE occurs late after termination of idraparinux but probably at the same rate as after termination of warfarin. ${ }^{15}$

\section{Atrial Fibrillation}

The phase III AMADEUS study was a randomized, open-label trial designed to compare the efficacy and safety of once-a-week idraparinux versus oral VKA treatment for the long-term prevention of thromboembolic events (stroke and non-central nervous system systemic embolism [non-CNS SE]) in patients with atrial fibrillation (AF) and at least one additional risk factor for stroke. A total of 4576 patients (2283 in the idraparinux group and 2293 in the VKA group) were randomized. Patients with AF who were eligible for VKA treatment were randomized to receive either subcutaneous idraparinux $2.5 \mathrm{mg}$ once a week or VKA therapy adjusted to achieve the target INR of 2.5 (range, 2 to 3 ). The study was powered to show noninferior efficacy of idraparinux compared with standard VKA treatment in patients with AF who require prolonged oral anticoagulation. The primary efficacy end point was the composite of all strokes (ischemic, hemorrhagic, and undefined) and non-CNS SE. The principal safety end point was the occurrence of major bleeding or clinically relevant non-major bleeding. The other safety outcome was all-cause mortality. The event rate of the composite end point of any strokes (ischemic, hemorrhagic, and undefined) and non-CNS SE was $0.9 \%$ with idraparinux and $1.3 \%$ with warfarin $(p=0.007)$, meeting the criteria for noninferiority. The incidence of clinically relevant bleeding, the primary safety outcome, was significantly higher in the idraparinux group than in the comparator group (19.7\% vs. $11.3 \%, p<0.0001)$, although no overall difference was observed in all-cause mortality between the two treatment groups. Bleeding appeared over time 
and was more pronounced in patients with impaired renal function and in the elderly (www.clinicaltrials.gov). These observations indicate the need to consider a dose reduction of idraparinux depending on these characteristics in patients with AF. This will be addressed in the new BOREALIS-AF study.

\section{Biotinylated Idraparinux}

Biotinylated idraparinux is structurally similar to idraparinux sodium with the addition of a biotin segment. It has the same anticoagulant activity as idraparinux in vivo and the same pharmacologic activity (pharmacokinetics and pharmacodynamics; PK/PD). Biotin has a strong and specific affinity for avidin, an egg protein, which can be given intravenously to rapidly bind, neutralize, and eliminate idraparinux and its anticoagulant activity.

The clinical development program has been designed in view of clinical results obtained with idraparinux. Bioequipotency studies in patients with DVT (EQUINOX) and in patients with PE (CASSIOPEA) were initiated comparing idraparinux with biotin-idraparinux. The bioequipotency study of biotinylated idraparinux and idraparinux includes 700 patients with DVT and contains a substudy on the neutralizing effect of avidin on the biotin-idraparinux induced anti-FXa activity. The primary outcome measure is the bioequipotency and avidin neutralizing effect assessment. The study aims to compare during a 6-month treatment the safety and effectiveness of biotinylated idraparinux with that of idraparinux, taking into account new events of DVT and PE and bleeding risk. Secondary outcome measures are PK/PD time courses to steady-state achievement (anti-FXa activity), bleeding adverse events and deaths within 6 months, and symptomatic recurrent DVT/PE (fatal or not) within 6 months (see www. ClinicalTrials.gov; identifier NCT00311090).

Patients with symptomatic PE are treated in a randomized, double-blind, double-dummy, parallel group study with biotinylated idraparinux $(3.0 \mathrm{mg}$ subcutaneously once-weekly) versus oral INR-adjusted warfarin $(n=3200)$. Primary outcome measures are recurrence of fatal and nonfatal venous thromboembolic events (DVT or PE) at 3 months. Secondary outcome measures are recurrence of VTE events at 6 months and bleedings over 3- and 6-month periods (see www. ClinicalTrials.gov).

In the AMADEUS trial, bleeding appeared over time and was more pronounced in patients with impaired renal function and in the elderly. These observations indicate the need to consider a dose reduction of idraparinux depending on these characteristics in $\mathrm{pa}^{-}$ tients with AF. This will be considered in the new BOREALIS-AF study, which is a multicenter, randomized, double-blind, assessor-blind, noninferiority study comparing the efficacy and safety of once-a-week subcutaneous biotinylated idraparinux with adjusted-dose warfarin in the prevention of stroke and systemic thromboembolic events in patients with AF. Treatment will be administered for a period of 6 months to 2 years. All patients will start with biotinylated idraparinux $3 \mathrm{mg}$ (equivalent to base idraparinux $2.5 \mathrm{mg}$ ) once a week for 7 weeks, and then the dose will be reduced depending on age and renal function (see http://en.sanofi-aventis.com/ Images/070711_idraparinux_en_tcm24-18621.pdf).

\section{OTHER PARENTERAL FXa INHIBITORS}

AVE5026 is a new ultralow-molecular-weight agent (Sanofi-Aventis, Paris, France) that has been evaluated for the prevention of postoperative VTE in patients undergoing total knee replacement in a phase IIb trial (see www.ClinicalTrials.gov; identifier NCT00331838).

SR123781 is a short-acting synthetic hexadecasaccharide, injected once daily, which is a powerful indirect inhibitor of FXa and FIIa coagulation factors. In the SHINE phase IIb study, SR123781 was evaluated in patients with non-ST-elevated acute coronary syndrome (see www.ClinicalTrials.gov; identifier NCT 00123565). The study demonstrated good safety with a bleeding rate similar to UFHs with or without abciximab. Phase III trials in acute coronary syndrome (ACS) will soon begin. The DRIVE phase IIb study evaluated the hexadecasaccharide in the prevention of venous thromboembolic events in patients undergoing total hip replacement (see www.ClinicalTrials.gov; identifier NCT00338897) and demonstrated a correlation between dose and clinical response, and also good efficacy and safety.

Otamixaban is a selective, synthetic direct FXa inhibitor. It has a fast onset of action and a short half-life and thus a suitable profile for use in patients with ACS treated invasively. The SEPIA-PCI phase IIa study demonstrated a good safety profile with predictable and dose-related anticoagulant activity (see www.ClinicalTrials.gov; identifier NCT00133731).

DX-9065a is a direct, small-molecule (571.07 $\mathrm{Da})$, selective, reversible FXa inhibitor that, owing to its small size, is able to inhibit both free FXa and FXa within the prothrombinase complex. ${ }^{16}$ It has a threecompartment distribution, is cleared renally, and at therapeutic doses has $\mathrm{a}, \mathrm{b}$, and $\mathrm{c}$ half-lives of $0.23,2.9$, and 89.9 hours, respectively. ${ }^{17}$ This results in a functional half-life ranging from 30 minutes to 6 hours depending on the duration of infusion. XaNADUACS was a phase II, multicenter, international, randomized, double-blinded, double-dummy, active-controlled study in patients with non-ST-elevation ACS. The composite end point of death, myocardial infarction (MI), or urgent revascularization occurred in $19.5 \%$ of patients assigned to heparin, $19.3 \%$ of patients assigned 
to low-dose DX-9065a, and $11.9 \%$ of patients assigned to high-dose DX-9065a (not significant). Patients assigned to either low- or high-dose DX-9065a tended to have less bleeding and required fewer transfusions than did those assigned to heparin. Rates of major or minor bleeding were similar among patients assigned to heparin (7.7\%) and high-dose DX-9065a (7.0\%) but was lower $(4.0 \%)$ in patients on low-dose DX-9065a. ${ }^{18}$ The benefit of DX-9065a compared with heparin is currently being investigated for this indication (see www.ClinicalTrials.gov; identifier NCT00317395).

\section{ORAL DIRECT FXa INHIBITORS}

Natural direct inhibitors of FXa include tick anticoagulant peptide (TAP) and antistasin. Both are available in recombinant forms. Although these agents have been shown to reduce arterial thrombosis and restenosis in animal models, because they are antigenic, neither has been tested in humans. The oral direct FXa inhibitors that are in clinical development include rivaroxaban (Bayer Healthcare), apixaban (BMS), YM150 (Astellas), otamixaban (Sanofi-Aventis), DU-176b (Daiichi), LY517717 (Lilly), and PRT054021 (Portola). This overview focuses on the currently most advanced oral direct FXa inhibitors rivaroxaban and apixaban. It should, however, be noted that these agents inhibit FXa within the assembled prothrombinase complex as well as free FXa, whereas fondaparinux is only able to inhibit the pool of free FXa in the blood. ${ }^{19}$

\section{Rivaroxaban}

Rivaroxaban is a synthetic small molecule directed against the active site of FXa. After oral administration, it is absorbed in the stomach and small intestine with a bioavailability of 60 to $80 \%$. Peak plasma levels are achieved within 3 hours, and the drug circulates with a half-life of 9 hours. Rivaroxaban is cleared via two pathways: $\sim 65 \%$ is excreted unchanged in the urine, and the remainder is eliminated through the biliary/fecal route. Because of the predominance of the renal pathway of excretion, the half-life of rivaroxaban is prolonged in the elderly and in patients with renal impairment. ${ }^{20}$

\section{DOSE FINDING IN POSTOPERATIVE PREVENTION OF VTE}

The proof of principle for the safety of rivaroxaban was investigated in patients undergoing elective total hip replacement. A randomized, double-blind, doubledummy, active-comparator controlled, dose-ranging study assessed the efficacy and safety of once-daily rivaroxaban relative to enoxaparin for prevention of VTE in these patients. Patients $(n=873)$ were randomized to once-daily oral rivaroxaban doses of $5,10,20,30$, or $40 \mathrm{mg}$ (initiated 6 to 8 hours after surgery) or a oncedaily subcutaneous enoxaparin dose of $40 \mathrm{mg}$ (given the evening before and $>6$ hours after surgery) for 5 to 9 days. The primary end point (composite of any DVT, objectively confirmed PE, and all-cause mortality) was observed in $14.9,10.6,8.5,13.5$, and $6.4 \%$ of patients receiving $5,10,20,30$, and $40 \mathrm{mg}$ rivaroxaban, respectively, and in $25.2 \%$ of patients receiving $40 \mathrm{mg}$ enoxaparin ( $n=618$, per-protocol population). No significant dose-response relationship was found for efficacy $(p=0.0852)$. Major postoperative bleeding was observed in $2.3,0.7,4.3,4.9$, and $5.1 \%$ of patients receiving $5,10,20,30$, and $40 \mathrm{mg}$ rivaroxaban, respectively, and in $1.9 \%$ of patients receiving $40 \mathrm{mg}$ enoxaparin ( $n=845$, safety population), representing a significant dose-response relationship $(p=0.0391)$. Major bleeding rates observed in the $5-\mathrm{mg}$ and $10-\mathrm{mg}$ rivaroxaban once-daily dose groups were similar to those with enoxaparin. When both efficacy and safety are considered, the results of this study suggest that $10 \mathrm{mg}$ rivaroxaban once daily should be investigated in future clinical studies. Dose-response relationships between rivaroxaban and the primary efficacy end point (DVT, nonfatal PE, all-cause mortality) and the primary safety end point (major postoperative bleeding events) are shown in Fig. $2 .{ }^{21}$

\section{TREATMENT OF ACUTE VTE}

The aim of this phase II dose-finding study was to explore the efficacy and safety of rivaroxaban, relative to standard therapy, for the treatment of acute proximal DVT. The randomized, parallel-group phase II trial in patients with proximal DVT explored the efficacy and safety of rivaroxaban 10,20 , or $30 \mathrm{mg}$ twice daily or $40 \mathrm{mg}$ once daily compared with enoxaparin $1 \mathrm{mg} / \mathrm{kg}$ twice daily followed by VKA for 12 weeks. The primary efficacy outcome was an improvement in thrombotic burden at day 21 compression (defined as a $\geq 4$-point reduction in the thrombus score as ultrasound measured by examination). The primary safety outcome was the incidence of major bleeding up to 2 days after the last dose. Secondary safety measures included the incidence of minor bleeding events. The primary efficacy end point was achieved in 53 of 100, 58 of 98, and 62 of 109 patients receiving rivaroxaban 10,20 , or $30 \mathrm{mg}$ twice daily, respectively, and in 49 of 112 patients receiving rivaroxaban $40 \mathrm{mg}$ once daily, compared with 50 of 109 patients treated with enoxaparin/VKA. There was no dose-response relationship between rivaroxaban and the primary efficacy end point $(p<0.67)$. At 3 months, the efficacy end point was also not different in patients randomized to the rivaroxaban doses and enoxaparin/ VKA. After 3 months, 2 symptomatic VTE events occurred each in the $10 \mathrm{mg}$ twice-daily (DVT and fatal PE), $20 \mathrm{mg}$ twice-daily (DVT and PE), and $30 \mathrm{mg}$ twice-daily (DVT and PE) groups, 3 in the $40 \mathrm{mg}$ daily group (DVT, PE, and fatal PE), and 1 in the enoxaparin/VKA group (DVT). 


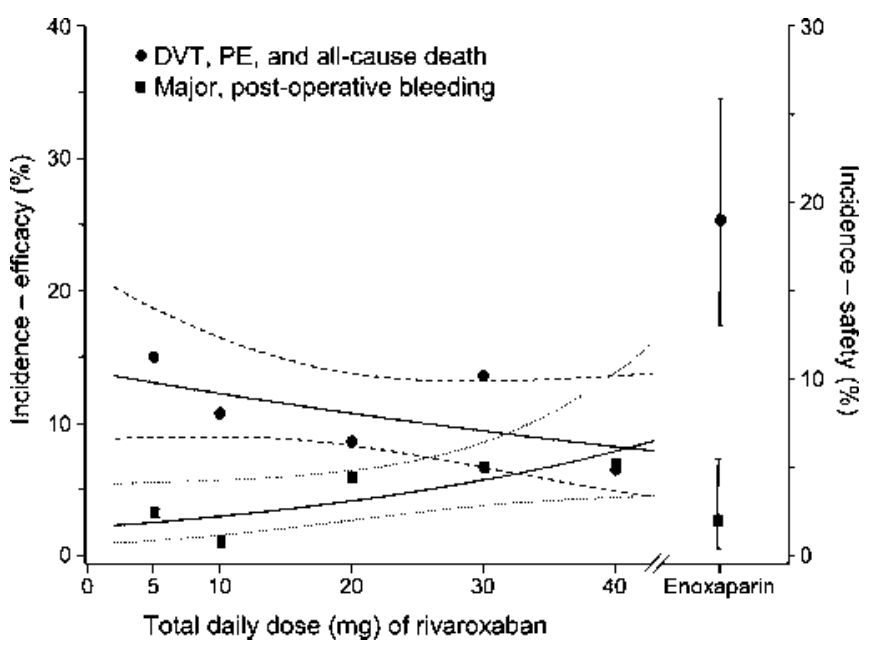

Figure 2 Dose-response relationships between rivaroxaban and the primary efficacy end point and the primary safety end point. The solid lines are the dose-response curves for rivaroxaban, estimated by logistic regression including total daily dose as a covariate. The dotted lines represent the 95\% confidence intervals for safety. The hatched lines represent the 95\% confidence intervals for efficacy. (From Eriksson BI et al. Circulation 2006;114:2374-2381, with permission.

Major bleeding was observed in 1.7, 1.7, and 3.3\% of patients receiving rivaroxaban 10,20 , or $30 \mathrm{mg}$ twice daily, respectively, in $1.7 \%$ of patients receiving $40 \mathrm{mg}$ rivaroxaban daily, and in none of the enoxaparin/vitamin $\mathrm{K}$ antagonist patients. There were no major bleeding events. ${ }^{22}$

Beyond 21 days, the pooled point estimates for alanine aminotransferase (ALT) elevations $>3$ times the upper limit of normal (ULN) were 1.9\% with rivaroxaban and $0.9 \%$ in the VKA group. Fatal liver failure in one patient was attributed to acute hepatitis B infection; however, a contribution from rivaroxaban or one of the other concomitant medications cannot be excluded.

The Einstein study is one of two analogous phase II trials evaluating the efficacy and safety of rivaroxaban for the treatment of DVT of similar design, but compared once-daily rivaroxaban $(20,30$, or $40 \mathrm{mg}$ ) with a heparin (either UFH or LMWH), followed by a VKA, in 543 patients with symptomatic DVT without symptomatic PE. The primary efficacy outcome was deterioration in thrombotic burden or symptomatic recurrent VTE, which occurred in 5.4 to $6.6 \%$ of patients on rivaroxaban and in $9.9 \%$ on heparin/VKA. Again, there was no evidence of a dose-efficacy relationship with rivaroxaban. During the first 3 weeks of treatment, the incidence of ALT elevations $>3$ times the ULN was lower in patients on rivaroxaban, but after 3 weeks, the incidences of elevations were low with both treatments. No patients in the enoxaparin/VKA group stopped treatment because of elevated liver enzymes, whereas three patients stopped treatment early in the rivaroxaban group. ${ }^{23}$ On the basis of these trials, the $20 \mathrm{mg}$ once-daily dose of rivaroxaban has been chosen for evaluation in phase III randomized trials.
Rivaroxaban $(1 \times 20 \mathrm{mg}$ daily $)$ is currently being investigated for prevention of recurrent VTE in patients with acute symptomatic DVT or PE and compared with initial anticoagulation with bodyweight-adjusted enoxaparin followed by INR-adjusted warfarin for 6 months. The primary efficacy outcome is symptomatic recurrent VTE documented objectively. In addition, death that cannot be attributed to a documented course and for which VTE cannot be ruled out is included into the end point. The study duration is 3,6 , or 12 months followed by a 30 -day observational period. Approximately 2900 patients suffering from acute DVT and $\sim 3300$ patients presenting with acute $\mathrm{PE}$ will be included in the study (see www.ClinicalTrials.gov; identifier NCT00440193).

The prolonged prophylaxis of VTE is being investigated in patients with an initial prophylaxis of VTE for 3 to 12 months and no indication for further anticoagulation. These patients are randomized to rivaroxaban $(1 \times 20 \mathrm{mg}$ daily $)$ or placebo in a double-blind, prospective, randomized clinical trial for 6 or 12 months. End points objectively documented a recurrent VTE including death that cannot be attributed to a documented course or for which VTE cannot be ruled out (see www.ClinicalTrials.gov; identifier NCT00439725, Einstein Extension).

\section{ATRIAL FIBRILLATION}

In patients with non-valvular AF, rivaroxaban is compared with INR-adjusted oral warfarin for prevention of stroke in a double-blind, double-dummy, prospective, randomized trial. This efficacy and safety trial of $20 \mathrm{mg}$ once-daily rivaroxaban in preventing thromboembolic events includes 14,000 patients. Patients with a reduced creatinine clearance between 30 and $49 \mathrm{~mL} / \mathrm{min}$ receive a reduced dose of $15 \mathrm{mg}$ rivaroxaban once daily. The 
primary composite outcome event consists of embolic and nonembolic stroke and non-CNS SE. The secondary outcome end points are a composition of stroke, non-CNS SE, and vascular death (see www.ClinicalTrials.gov; identifier NCT 004403767, Rocket trial).

The efficacy and safety of rivaroxaban for the prevention of stroke and embolism in 1200 subjects with non-valvular AF are currently being investigated in a prospective, randomized, double-blind, phase III trial in Japan. Rivaroxaban $1 \times 15 \mathrm{mg}$ daily (subjects with a creatinine clearance between 30 and $45 \mathrm{~mL} / \mathrm{min}$ will receive $10 \mathrm{mg}$ ) are randomly compared with INRadjusted warfarin for 1 to 2.5 years. The primary outcome composite end point consists of major and nonmajor clinically relevant bleeding and a composite of stroke and non-CNS SE. The secondary outcome end points are major and minor bleeding events and any other adverse events as well as the composite outcome of stroke, non-CNS SE, and vascular death (see www.ClinicalTrials.gov; identifier NCT 00494871).

\section{ACUTE CORONARY SYNDROME}

In patients with ACS, a randomized, double-blind, placebo-controlled, multicenter, dose-escalating study is being performed to evaluate the safety and efficacy of rivaroxaban in combination with aspirin alone or with aspirin and thienopyridine in 1350 patients. The primary outcome end points are safety of rivaroxaban in patients with recent coronary syndrome, including ST-elevation $\mathrm{MI}$, non-ST-elevation MI, or unstable angina who are treated with aspirin alone or aspirin plus clopidogrel. Secondary outcome measures are benefit risk assessments and the overall safety of rivaroxaban (see www.ClinicalTrials.gov; identifier NCT 00402597, the Atlas ACS TIMI 46 trial).

\section{Apixaban}

Apixaban is a follow-up compound to the oral, direct FXa inhibitor razaxaban and is believed to have a superior risk-to-benefit ratio with respect to bleeding. Apixaban is a highly selective and potent $\left(\mathrm{K}_{\mathrm{i}}=0.8 \mathrm{nM}\right)$ inhibitor of both free and prothrombinase-bound $\mathrm{FXa}$. In animal models, the compound was found to have a high oral bioavailability $(51,88$, and $34 \%$ in chimpanzees, dogs, and rats, respectively), multiple pathways of elimination, including renal and fecal excretion, and minimal potential for drug-drug interactions and the formation of reactive metabolites. ${ }^{24}$ Furthermore, it demonstrated potent antithrombotic effects in a rabbit model of venous thrombosis at doses that preserved hemostasis.

\section{DOSE FINDING IN POSTOPERATIVE PREVENTION OF VTE}

A phase IIb study of apixaban for the prevention of VTE in patients undergoing total knee replacement has recently been completed. The randomized study compared six doses of oral, double-blind apixaban $(5,10$, or $20 \mathrm{mg}$ given as a single or twice-daily divided dose) with openlabel enoxaparin or warfarin for 10 to 14 days in 1217 patients. The primary efficacy consisted of DVT confirmed by bilateral venogram, symptomatic DVT, nonfatal PE, and death from any cause. The primary outcome rate decreased with increasing apixaban dose ( $p=0.09$ with daily/twice-daily regimens combined, $p=0.19$ for daily and $p=0.13$ for twice-daily dosing). The primary outcome rates for apixaban $2.5 \mathrm{mg}$ twice daily and $5 \mathrm{mg}$ daily were $9.0 \%$ and $11.3 \%$, respectively, compared with $15.6 \%$ in the enoxaparin and $26.6 \%$ in the warfarin groups. Patients on the different apixaban doses had a relative risk reduction in the primary outcome ranging from 21 to $69 \%$ when compared with enoxaparin and from 53 to $82 \%$ when compared with warfarin. Total VTE rates were lower in the twice-daily than in the daily apixaban groups. For the composite outcome of proximal DVT, PE, and all-cause mortality, each apixaban group had a lower event rate (0 to 2.7\%) compared with the enoxaparin group (4.6\%). The incidence of the primary efficacy end point in the apixaban groups combined was lower than in the enoxaparin and warfarin groups ( $p=0.02$ and $p=0.01$, respectively).

The incidence of major bleeding among apixabantreated patients ranged from 0 ( $2.5 \mathrm{mg}$ twice daily) to $3.3 \%$ ( $20 \mathrm{mg}$ daily); no major bleeding was observed in either the enoxaparin or warfarin groups. The frequencies of major bleeding were comparable for twice-daily and daily apixaban groups. The overall incidences of minor bleeding during apixaban, enoxaparin, and warfarin treatment were 0.7 to $7.2 \%, 4.0 \%$, and $5.3 \%$, respectively. A dose-related response was noted for the incidence of minor bleeding across the daily apixaban treatment groups $(p=0.01)$ but not for twice-daily groups $(p=0.07)$. There was a low incidence of major bleeding with apixaban (0 to $3.3 \%$ vs. an unexpectedly low rate of 0 in enoxaparin and warfarin groups). The data of VTE and bleeding are depicted in Fig. 3.

Deaths were due to fatal PE (2.5 mg twice daily; after 8 days of study medication); MI (2.5 mg twice daily; diagnosis after 4 days of study medication, died 3 weeks later); and end-stage heart failure and cachexia (20 mg daily; died 6 weeks after 5 days of study medication).

Two patients (apixaban $10 \mathrm{mg}$ twice daily and warfarin) had a single, concurrent elevation in ALT $>3$ times ULN and total bilirubin $>2$ times ULN on postoperative day 1 , which returned to below these thresholds by the next evaluation and to within normal limits by the end of the treatment period (apixaban subject) or at the 30-day follow-up period (warfarin subject) with continued drug dosing. ${ }^{25}$

\section{TREATMENT OF ACUTE VTE}

The efficacy and safety of apixaban was evaluated in patients with confirmed DVT. Patients were randomly 


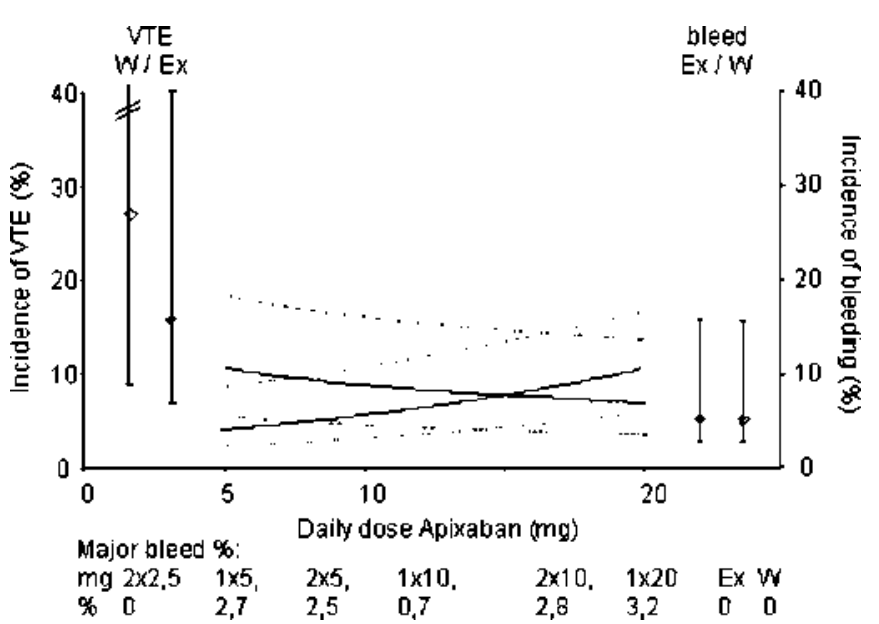

Figure 3 Dose-response relationships between apixaban and the incidences of VTE and bleeding. The solid lines are the mean dose-response curves for apixaban for the daily doses. The dotted lines represent the min and max values for VTE (longer dots) and the bleeding (shorter dots). The major bleeds are shown below the figure for each treatment dose of apixaban. E, enoxaparin; W, warfarin. (Adapted from Lassen MR et al. J Thromb Haemost 2007;5:2368-2375).

allocated to one of three double-blind regimens of apixaban $(5 \mathrm{mg}$ twice daily, $10 \mathrm{mg}$ twice daily, or 20 $\mathrm{mg}$ daily) or to conventional treatment with LMWH or fondaparinux followed by open-label VKA (dose adjusted to an INR of 2.0 to 3.0). Five hundred twenty patients were included and treated for 84 to 91 days. A bilateral venous compression ultrasound (CUS) of the legs and a perfusion lung scan (PLS) were performed within 36 hours from randomization and at 12 weeks (Boticelli trial).

The primary efficacy outcome was the composite of symptomatic recurrent VTE and deterioration of the thrombotic burden as assessed by repeat bilateral CUS and PLS. The principal safety outcome was a composite of major and clinically relevant non-major bleeding.

For apixaban $5 \mathrm{mg}$ twice daily, $10 \mathrm{mg}$ twice daily, $20 \mathrm{mg}$ daily, and for VKA, the primary efficacy outcome rates were $6.0,5.6,2.6 \%$ and $4.2 \%$, respectively (Table 5). The principal safety outcome rates were 8.6,
4.5, 7.3\% and 7.9\%, respectively. The rates of symptomatic VTE were 2.6, 3.2, 1.7\% and 2.5\%, respectively, and the rates of major bleeding were $0.8,0,0.8 \%$ and 0 , respectively (Table 6). A fixed dose of apixaban seems to be as safe as enoxaparin/warfarin for treatment of acute VTE. ${ }^{26}$

In a phase III randomized clinical trial, the oral direct FXa inhibitor apixaban dosing $10 \mathrm{mg}$ twice daily for 1 week followed by $5 \mathrm{mg}$ twice daily is being investigated in patients with acute DVT and PE for noninferiority to initial body-weight-adjusted enoxaparin followed by INR-adjusted warfarin. Primary objectives are the incidences of recurrent VTE or VTErelated death over 6 months of therapy. The doubleblind design includes a double-dummy study of the INR values. About 4800 patients are included into the study.

The prolonged prophylaxis after an acute episode of VTE is being investigated using the oral FXa inhibitor apixaban versus placebo for an extended prophylaxis of VTE in those patients with no indication for a

Table 5 Recurrent VTE and Other Efficacy End Points of the Dose-Finding Study of Apixaban for Treatment of VTE

\begin{tabular}{|c|c|c|c|c|}
\hline & $\begin{array}{l}\text { Apixaban } \\
5 \mathrm{mg} \text { b.i.d. } \\
(N=117)\end{array}$ & $\begin{array}{l}\text { Apixaban } \\
10 \mathrm{mg} \mathrm{b.i.d.} \\
(N=125)\end{array}$ & $\begin{array}{l}\text { Apixaban } \\
20 \mathrm{mg} 0 . \mathrm{d} . \\
(N=116)\end{array}$ & $\begin{array}{l}\text { LMWH } \\
\text { and VKA } \\
(N=118)\end{array}$ \\
\hline $\begin{array}{l}\text { Symptomatic VTE, } \\
\text { CUS or PLS } \\
\text { deterioration, } n\end{array}$ & 7 & 7 & 3 & 5 \\
\hline Event rate (\%) & 6.0 & 5.6 & 2.6 & 4.2 \\
\hline $95 \% \mathrm{Cl}$ & $(2.4,11.9)$ & $(2.3,11.2)$ & $(0.5,7.4)$ & $(1.4,9.6)$ \\
\hline Fatal PE, $n$ & 0 & 0 & 1 & 0 \\
\hline Nonfatal PE, $n$ & 0 & 0 & 0 & 1 \\
\hline Symptomatic DVT, $n$ & 3 & 4 & 1 & 2 \\
\hline CUS/PLS deterioration, $n$ & 4 & 3 & 1 & 2 \\
\hline
\end{tabular}

o.d., daily; b.i.d., twice daily; $\mathrm{Cl}$, confidence interval. 
Table 6 Bleeding Events of the Dose-Finding Study of Apixaban for Treatment of VTE

\begin{tabular}{|c|c|c|c|c|}
\hline & $\begin{array}{l}\text { Apixaban } \\
5 \mathrm{mg} \text { b.i.d. } \\
(N=128)\end{array}$ & $\begin{array}{l}\text { Apixaban } \\
10 \mathrm{mg} \text { b.i.d. } \\
(N=133)\end{array}$ & $\begin{array}{l}\text { Apixaban } \\
20 \text { mg o.d. } \\
(N=124)\end{array}$ & $\begin{array}{l}\text { LMWH } \\
\text { and VKA } \\
(N=126)\end{array}$ \\
\hline $\begin{array}{c}\text { Major or clinically relevant } \\
\text { non-major bleeding, } n\end{array}$ & 11 & 6 & 9 & 10 \\
\hline Event rate $(\%)$ & 8.6 & 4.5 & 7.3 & 7.9 \\
\hline $95 \% \mathrm{Cl}$ & $(4.4,14.9)$ & $(1.7,9.6)$ & $(3.4,13.3)$ & $(3.9,14.1)$ \\
\hline Major bleeding, $n$ & 1 & 0 & 1 & 0 \\
\hline Event rate (\%) & 0.8 & 0 & 0.8 & 0 \\
\hline $95 \% \mathrm{Cl}$ & $(0,4.3)$ & $(0,2.7)$ & $(0,4.4)$ & $(0,2.9)$ \\
\hline
\end{tabular}

b.i.d., twice daily; o.d., daily; $\mathrm{Cl}$, confidence interval.

prolonged prophylaxis of VTE using VKA. Apixaban $2.5 \mathrm{mg}$ twice daily is being compared with $5 \mathrm{mg}$ apixaban twice daily and placebo twice daily for 12 months. Primary end point is a determination of at least one of the apixaban dose regimens to be superior to placebo. The combined end point consists of symptomatic recurrent VTE and all-cause mortality in subjects who have completed a standard of 6 to 12 months of conventional anticoagulation for prevention of a symptomatic DVT or $\mathrm{PE}$ in $\sim 650$ patients per group (see www.clinicaltrials. gov).

\section{ATRIAL FIBRILLATION}

A phase III study has been initiated to evaluate the efficacy and safety of apixaban, compared with warfarin, for the prevention of stroke and systemic embolism in patients with non-valvular AF. Secondary outcome measures are confirmed ischemic stroke, hemorrhagic stroke, systemic embolism, and all-cause mortality. This randomized, double-blind, parallelarm study is expected to enroll 15,000 patients (see www.ClinicalTrials.gov; identifier NCT00412984, Aristotle trial).

Another phase III prospective, randomized, double-blind clinical trial investigates the prevention of stroke in patients with $\mathrm{AF}$ who have failed or are unsuitable for VKA treatment. Patients are randomized to $2 \times 2.5 \mathrm{mg}$ daily apixaban versus acetylsalicylic acid (ASA; 81 to $324 \mathrm{mg}$ daily) in a double-blind design. The study hypothesis is the superiority of apixaban to ASA for preventing the completed outcome of stroke or systemic embolism in patients with $\mathrm{AF}$ with at least one additional risk factor for stroke. A total of 5600 patients are planned to be randomized into the study with a duration of up to 3 years (see www.ClinicalTrials.gov; identifier NCT00496769, AVERROES).

\section{PREVENTION OF VTE IN HOSPITALIZED MEDICAL PATIENTS}

In a phase III randomized, double-blind, multicenter trial, the safety and efficacy of $2 \times 2.5 \mathrm{mg}$ daily apixaban for $\sim 35$ to 35 days is compared with $1 \times 40 \mathrm{mg}$ daily enoxaparin for $\sim 10$ to 15 days during hospitalization followed by placebo over 30 days in acutely ill medical subjects during and after hospitalization for prophylaxis of VTE. Approximately 6500 patients will be randomized to apixaban or enoxaparin/placebo. The primary efficacy outcomes are a composite end point of VTE and VTE-related death during the 30-day double-blind treatment period. Total VTE is defined as the combination of symptomatic DVT, fetal or nonfetal symptomatic $\mathrm{PE}$, and asymptomatic proximal DVT detected by CUS. VTE-related death is defined as sudden death for which VTE cannot be excluded as a cause. This is a phase III superiority randomized clinical trial (see www.ClinicalTrials.gov; identifier NCT00457002, ADOPT).

\section{OTHER INDICATIONS}

One study, potentially involving up to 1800 patients, has begun to assess the efficacy and safety of apixaban in patients who have recently had unstable angina or a heart attack (see www.ClinicalTrials.gov; identifier NCT00313300). Another study currently under way is investigating apixaban for the prevention of thromboembolic events in patients with advanced metastatic cancer and is expected to enroll 160 patients (see www.ClinicalTrials.gov; identifier NCT00320255).

\section{LY517717}

In preclinical studies, $\mathrm{LY} 517717$ was shown to have a $\mathrm{K}_{\mathrm{i}}$ of 4.6 to $6.6 \mathrm{nM}$, an oral bioavailability of 25 to $82 \%$, and a 1000-fold greater selectivity for FXa than related serine proteases. It also demonstrated antithrombotic effects both in vitro and in vivo in a rat arteriovenous shunt model, and studies in dogs indicated that the compound did not have associated bleeding issues. LY517717 was well tolerated in healthy subjects with a half-life of $\sim 25$ hours. Elimination of LY517717 appeared to be primarily via the gastrointestinal route. ${ }^{27}$

Based on these findings, a phase II double-blind, double-dummy, dose-ranging study was initiated to 
determine the efficacy and safety of LY517717, compared with enoxaparin, for the prevention of VTE in patients undergoing total knee replacement or total hip replacement. Patients $(n=511)$ were randomized to receive oral LY517717 $(25,50,75,100,125$, or $150 \mathrm{mg}$ daily) initiated postoperatively or enoxaparin $40 \mathrm{mg}$ daily initiated the evening before surgery. The primary efficacy end point of the study was the incidence of VTE, and safety end points were the incidences of major and minor bleeding up to 30 days after treatment initiation. Because of lack of efficacy, the three lowest LY517717 dose arms were stopped early, and the study was completed with the three highest doses only. The 100, 125, and $150 \mathrm{mg}$ daily doses of LY517717 were not inferior to enoxaparin, with similar incidences of the efficacy end point ( 17.1 to $24.0 \%$ vs. $22.2 \%$ with enoxaparin) and lower incidences of major bleeding ( 0 to $0.9 \%$ vs. $1.1 \%$ with enoxaparin) and minor bleeding (0 to $1.0 \%$ vs. $2.2 \%$ with enoxaparin). Dose-response relationships were observed between concentration of LY517717 and prolongation of PT. Gender and creatinine clearance affected LY517717 concentration. ${ }^{28}$

\section{YM150}

The compound YM150 has a $\mathrm{K}_{\mathrm{i}}$ for FXa of $31 \mathrm{nM}$ and inhibits prothrombin activation induced by free $\mathrm{FXa}$, prothrombinase, and whole-blood clots. YM150 demonstrated potent antithrombotic effects in animal models of venous and arterial thrombosis at doses that did not prolong bleeding time; this in vivo antithrombotic activity was also produced by its active metabolite, YM222714. In phase I studies, the drug has been shown to be well tolerated with predictable PK/PD in healthy volunteers. Food was not found to interfere with the absorption of YM150. ${ }^{29}$ PK effects correlated with PD effects, and a dose-response relationship between YM150 and PD was observed.

YM150 was investigated in patients $(n=174)$ undergoing hip replacement surgery to assess the safety and efficacy of thromboprophylaxis in a dose-escalation study. Patients were randomized per cohort to oral oncedaily YM150 or subcutaneous enoxaparin (40 mg daily) for 7- to 10-day treatment. The YM150 doses were 3, 10,30 , and $60 \mathrm{mg}$ by sequential dose escalation. The primary end point was major and/or clinically relevant non-major bleeding. No major bleeds and three clinically relevant non-major bleeds were reported, one in the $3 \mathrm{mg}$ and two in the $10 \mathrm{mg}$ groups. A dose-related trend in VTE incidence was found $(p=0.006)$. VTE with enoxaparin was $38.7 \% .^{30} \mathrm{~A}$ double-blind, dosefinding phase IIb study (ONYX-2) has now been initiated to confirm the efficacy and safety of YM150 in patients undergoing THR (see www.ClinicalTrials.gov; identifier NCT00353678).

\section{DU-176b}

In vitro studies have revealed that the $\mathrm{K}_{\mathrm{i}}$ for human $\mathrm{FXa}$ is $\sim 10,000$ times lower than the lowest $\mathrm{K}_{\mathrm{i}}$ value for any other human serine proteases (thrombin), indicating that DU-176b is highly specific for FXa. Its absorption is rapid, with a plasma half-life of 8.6 to 10.7 hours, and it is cleared mainly through the kidneys. The antithrombotic effect was evaluated in a phase I study. Antithrombotic effects were assessed by comparing ex vivo thrombus. Under venous flow after 1.5 and 5 hours, the thrombus was $28 \%$ and $21 \%$ smaller versus baseline, respectively $(p$ $<0.05)$. Under arterial condition, the reduction was $26 \%$ and $17 \%(p<0.05)$. Thrombin generation decreased by $28 \%$ at 1.5 hours and $10 \%$ at 5 hours. Changes in PT and INR correlated well with plasma drug concentrations $(\mathrm{R}=0.79$ and 0.78$)$. Pharmacologic analyses showed that DU-176b was scarcely metabolized and suggested the potential for convenient daily dosing. ${ }^{31}$

A phase IIa open-label dose-finding study of DU$176 \mathrm{~b}$ for the prevention of VTE after THR was initiated (see www.clinicaltrials.gov; identifier NCT00107900), involving $\sim 600$ patients. Results of this trial are not yet available. Phase IIb studies with DU-176b for the prevention of VTE and the prevention of stroke in patients with AF are in the planning stages. Studies in patients with acute coronary syndromes are planned, too.

\section{PRT054021}

Formerly known as MLN-1021, the oral PRT054021 has a $\mathrm{K}_{\mathrm{i}}$ for FXa of $0.117 \mathrm{nM}$, bioavailability of $47 \%$, and a half-life of 19 hours. PRT054021 demonstrated antithrombotic activity in animal models and was well tolerated at a wide range of doses in a phase I doseescalation study involving 64 patients. The half-life suggests a potential for daily dosing and had predictable PK and PD effects, as well as minimal interactions with food. PRT054021 was excreted almost unchanged in bile.

A multicenter, randomized phase II study has recently been initiated to evaluate the safety and efficacy of PRT054021 $40 \mathrm{mg}$ twice daily and $15 \mathrm{mg}$ twice daily compared with enoxaparin $30 \mathrm{mg}$ for the prevention of VTE in $\sim 200$ patients undergoing TKR (see www.clinicaltrials.gov; identifier NCT00375609). There are also plans to develop PRT054021 for the prevention and treatment of DVT, the prevention of stroke in patients with $\mathrm{AF}$, and the secondary prevention of stroke and MI.

\section{FXa Inhibitor 813893}

The direct FXa inhibitor 813893 (GlaxoSmithKline, London, United Kingdom) is in phase II for the prevention of VTE after orthopedic surgery and in phase I for the prevention of stroke in patients with AF. Preclinical data showed that this compound had a $\mathrm{K}_{\mathrm{i}}$ 
of $7 \mathrm{nM}$ for $\mathrm{FXa}$, a bioavailability of $91 \%$ in rats and $>55 \%$ in dogs, and no cytochrome $\mathrm{P} 450$ interactions. Phase I studies demonstrated that 813893 was well tolerated with linear PK.

\section{THROMBIN INHIBITORS}

Thrombin is another target for selective oral thrombin inhibitors. Thrombin not only converts fibrinogen to fibrin but also activates FXIII. Thrombin renders fibrin resistant to fibrinolysis by inhibiting cross-linking of fibrin and cross-linking of $\alpha_{2}$-antiplasmin to fibrin. Other prothrombotic roles of thrombin result in platelet activation, positive feedback on coagulation factors $\mathrm{V}$, VIII, and XI, and antithrombotic roles in the activation of protein $\mathrm{C}$ and thrombin activatable fibrinolysis inhibitor. Thrombin is the principal activator of platelets at sites of injury through its interaction with platelet protease activated receptors (PAR) -1 and $-4{ }^{32}$ Direct thrombin inhibitors inactivate fibrin-bound thrombin, in addition to fluid-phase thrombin. Consequently, they may attenuate thrombus accretion more effectively. Further, direct thrombin inhibitors produce a more predictable anticoagulant effect than does heparin because they do not bind to plasma proteins and are not neutralized by platlet factor 4 and highmolecular-weight multimers of von Willebrand factor generated at sites of vascular injury. ${ }^{33}$

Three parenteral direct thrombin inhibitors have been licensed for limited indications. Hirudin and argatroban are approved for the treatment of heparin-induced thrombocytopenia, whereas bivalirudin is licensed as an alternative to heparin in patients undergoing percutaneous coronary indications. ${ }^{34}$

\section{Ximelagatran}

The first orally available direct thrombin inhibitor, ximelagatran is an uncharged lipophilic drug with little intrinsic activity against thrombin. Melagatran is a dipeptide mimetic of the region of fibrinopeptide A that interacts with thrombin's active site. Melagatran has poor oral bioavailability and must be given subcutaneously. Ximelagatran is well absorbed from the gastrointestinal tract with a bioavailability of $\sim 20 \%$ and undergoes rapid biotransformation to melagatran via two intermediate metabolites, H338/57 and H415/ $04 .{ }^{35}$ Ximelagatran has a plasma half-life of 3 to 4 hours in healthy volunteers and 4 to 5 hours in patients. Because melagatran, the active agent, is eliminated via the kidneys, however, dose adjustments may be needed in patients with severe renal insufficiency. As with other direct thrombin inhibitors, there is no antidote for ximelagatran. ${ }^{36}$

Ximelagatran has been evaluated and shown to have efficacy in several settings, including thrombopro- phylaxis in high-risk orthopedic patients, treatment of VTE, prevention of cardioembolic events in patients with non-valvular AF, and prevention of recurrent ischemia in patients with recent MI.

Additional smaller investigations were done after termination of the treatment of acute VTE, and prophylaxis of recurrent events has been investigated in the THRIVE (thrombin inhibitor in venous thromboembolism) Treatment trial and the THRIVE III trial. The time course of the ALT and in addition of aspartate aminotransferase (AST) were analyzed. ALT increases dose-dependently during therapy with ximelagatran. The less frequent and lower increase of AST values compared with ALT values indicates a nontoxic effect of ximelagatran on liver cells. ${ }^{37}$

Recurrent thromboembolic events were also investigated in patients with VTE recruited at the German study centers, who were followed up for an additional 18 months, treated initially with $2 \times 24 \mathrm{mg}$ ximelagatran daily or placebo over 18 months (THRIVE III study). Zero of 9 versus 5 of 14 patients randomized to ximelagatran and placebo developed recurrent VTE including 1 fatal PE ( $p=0.0501)$. During follow-up, 3 of 9 and 0 of 9 patients initially randomized to ximelagatran and placebo, respectively, developed recurrent VTE. Thromboembolic events may reoccur in patients with acute VTE after termination of treatment with ximelagatran. ${ }^{38}$

A New Drug Application (NDA) was filed in the United States for ximelagatran for the indications of DVT prophylaxis after total knee replacement, secondary prophylaxis of VTE after initial anticoagulant therapy, and stroke prevention in AF. Because of concerns about hepatotoxicity, the Food and Drug Administration (FDA) denied approval of ximelagatran in 2004; the review also raised other issues related to the design and interpretation of the results of several of the studies and the potential for an increased risk of coronary events after the discontinuation of ximelagatran after major orthopedic surgery. In the AF trials, the relatively low frequency of thromboembolic events in the warfarin comparator group coupled with the need to choose an appropriate noninferiority margin would mandate the inclusion of a considerably larger number of patients with AF in trials of other new oral anticoagulants for this indication. ${ }^{39}$ Although a regimen of ximelagatran along with subcutaneous melagatran in the perioperative period had previously been approved in Europe for the short-term prophylaxis of DVT after major orthopedic surgery, the drugs were removed from the market in 2006. The ximelagatran program nevertheless demonstrated that fixed doses of an oral anticoagulant without routine coagulation monitoring can be as efficacious in preventing thrombosis and as safe with respect to major bleeding as warfarin in adults with satisfactory renal function. This strategy is now used in clinical trials of other oral direct thrombin and FXa inhibitors. ${ }^{40}$ 


\section{Dabigatran}

Dabigatran etexilate is an orally available prodrug that is converted to dabigatran, the active moiety. It is a potent, competitive, and reversible direct inhibitor of thrombin. Peak dabigatran plasma concentrations occur 0.5 to 2 hours after oral administration, resulting in a rapid onset of action. There is a biexponential distribution phase with a terminal half-life of 12 to 17 hours. As much as $80 \%$ of the drug is excreted unchanged by the kidneys. The average absolute bioavailability of dabigatran is $6.5 \%{ }^{41}$

Dabigatran etexilate is undergoing evaluation for the prevention of VTE after orthopedic surgery. In a multicenter, parallel-group, double-blind study, 1973 patients undergoing total hip or knee replacement were randomized to 6 to 10 days of oral dabigatran etexilate (50 or $150 \mathrm{mg}$ twice daily, $300 \mathrm{mg}$ once daily, $225 \mathrm{mg}$ twice daily), starting 1 to 4 hours after surgery or to subcutaneous enoxaparin $(40 \mathrm{mg}$ once daily) starting 12 hours prior to surgery. The primary efficacy outcome was the incidence of VTE (detected by bilateral venography or symptomatic events) during treatment. A total of 1464 (75\%) patients were evaluable for the efficacy analysis. VTE occurred in 28.5, $17.4,16.6$, and $13.1 \%$ of patients assigned to dabigatran etexilate 50 or $150 \mathrm{mg}$ twice daily, $300 \mathrm{mg}$ once daily, or $225 \mathrm{mg}$ twice daily, respectively, and in $24 \%$ of patients assigned to enoxaparin. A significant dosedependent decrease in VTE occurred with increasing doses of dabigatran etexilate $(p<0.0001)$. Compared with enoxaparin, VTE incidence was significantly lower in patients receiving $150 \mathrm{mg}$ twice daily $(p=0.04), 300$ $\mathrm{mg}$ once daily $(p=0.02)$, and $225 \mathrm{mg}$ twice daily $(p=0.0007)$. Compared with enoxaparin, major bleeding was significantly lower with $50 \mathrm{mg}$ twice daily $(0.3 \%$ vs. $2.0 \%, p=0.047)$ but elevated with higher doses with the $300 \mathrm{mg}$ once-daily dose $(4.7 \%, p=0.051)$.
A logistic regression analysis model of $\mathrm{C}_{\max }$ after administration of the first dose showed a strong correlation with efficacy and safety outcomes (Fig. 4). Within the range of clinically relevant (major plus clinically significant) bleeding events were seen in the study (ranging from 2 to 5\%). A 5\% rate of clinically relevant bleeding corresponded with a predicted $\mathrm{C}_{\max }$ of dabigatran of $40 \mathrm{ng} / \mathrm{mL}$. At this plasma concentration, the first dose of dabigatran etexilate is predicted to be $75 \mathrm{mg}$ with a DVT rate of $13 \% .{ }^{42}$

\section{TREATMENT AND PROLONGED PROPHYLAXIS OF \\ ACUTE VTE}

The treatment of acute DVT and PE is being investigated in a phase III randomized, double-blind, parallel-group study of the efficacy and safety of oral dabigatran etexilate $(150 \mathrm{mg}$ twice daily) compared with warfarin (INR 2.0 to 3.0) for 6-month treatment of acute symptomatic VTE, following initial treatment (5 to 10 days) with a parenteral anticoagulant approved for this indication (see www.ClinicalTrials.gov; identifier NCT00291330, RE-COVER). Primary end point of the study is the incidence of recurrent symptomatic objectively documented VTE during 6 months of treatment. The study is planned to include $\sim 10,500$ patients to demonstrate the noninferiority of treatment with dabigatran etexilate. The trial is performed in a double-blind and double-dummy fashion including sham INR values of patients treated with dabigatran.

The prolonged prophylaxis of recurrent VTE is being studied for an additional 18 months in a phase III randomized, double-blind, double-dummy clinical trial comparing the efficacy and safety of $150 \mathrm{mg}$ dabigatran etexilate twice daily to INR-adjusted warfarin after an initial anticoagulant therapy of 3 to 12 months (see www.ClinicalTrials.gov; identifier NCT00329238,

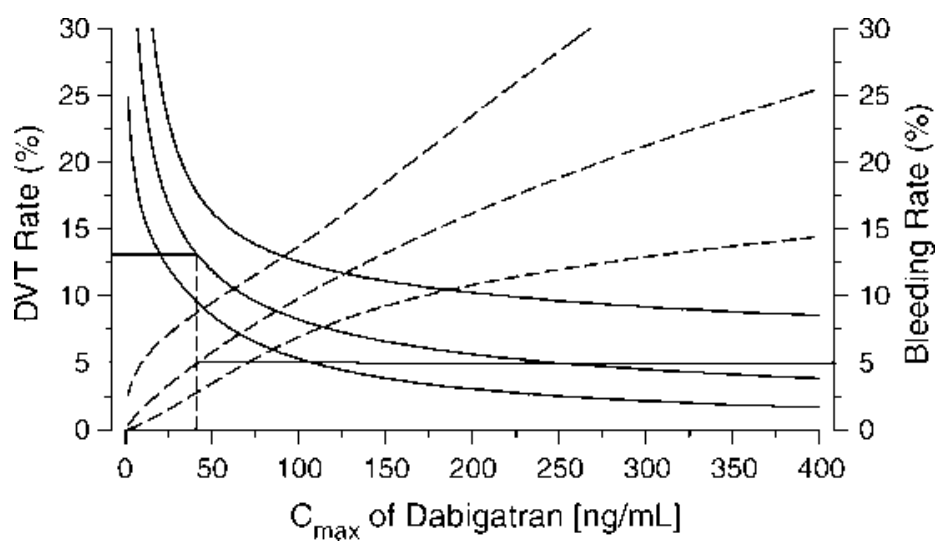

Figure 4 Logistic regression analysis of $C_{\max }$ on day 1 versus DVT rate (solid curves) and clinically relevant (major plus clinical significant) bleeding (dashed curves). The median percentage of events and corresponding 95\% confidence intervals are demonstrated. A $5 \%$ rate of clinically relevant bleeding (solid horizontal line) corresponds with a predicted dabigatran plasma concentration of $40 \mathrm{ng} / \mathrm{mL}$ and a DVT rate of 13\%. (From Eriksson Bl et al. J Thromb Haemost 2005;3:103-111, with permission). 
REMEDY). The primary end points are actively confirmed symptoms of recurrent VTE. At least 2000 patients will be required to demonstrate noninferiority of dabigatran etexilate.

In a second study, the prolonged prophylaxis of recurrent VTE is being studied for an additional 18 months in a phase III randomized, double-blind clinical trial comparing the efficacy and safety of 150 $\mathrm{mg}$ dabigatran etexilate twice daily with placebo after an initial anticoagulant therapy of 6 to 18 months. The primary end points are actively confirmed symptoms of recurrent VTE. About 2000 patients will be required to demonstrate the superiority of dabigatran (see www.ClinicalTrials.gov; identifier NCT00558259, RESONATE).

\section{ATRIAL FIBRILLATION}

In the PETRO trial, three doses of dabigatran etexilate $(50,150$, and $300 \mathrm{mg}$ twice daily) were combined with no ASA or $81 \mathrm{mg}$ or $325 \mathrm{mg}$ ASA once daily in patients with AF. Patients received warfarin alone (INR 2 to 3 ) in the comparator group. The trial was double-blind with respect to dabigatran dose but open-label for concomitant ASA treatment and for randomization between dabigatran and warfarin groups. Randomization was stratified in the ratio 6:9:9:4 (50, 150, and $300 \mathrm{mg}$ dabigatran, and warfarin, respectively). The primary outcome was the frequency of bleeding events.

Major bleeding events were limited to the group treated with $300 \mathrm{mg}$ dabigatran twice daily plus ASA (4 of 64). The rate was statistically different compared with the group treated with dabigatran $300 \mathrm{mg}$ twice daily without ASA (0 of $105, p=0.02$ ). There was a significant difference in major plus clinically relevant bleeding episodes (11 of 64 vs. 6 of 105, $p=0.03$ ) and total bleeding episodes (25 of 64 vs. 14 of 105 , $p=0.0003$ ) between $300 \mathrm{mg}$ dabigatran twice daily plus ASA and $300 \mathrm{mg}$ dabigatran twice daily without ASA. The frequency of bleeding in the group treated with $50 \mathrm{mg}$ dabigatran twice daily was significantly lower than that in the warfarin group: 7 of 107 versus 12 of 70 $(p=0.044)$. When the doses of dabigatran were compared with each other, irrespective of aspirin assignment, there were differences in total bleeding episodes in the $300 \mathrm{mg}$ twice-daily and $150 \mathrm{mg}$ twice-daily groups versus the $50 \mathrm{mg}$ twice-daily group ( 37 of 169 and 30 of 169 vs. 7 of $107, p=0.0002$ and $p=0.01$, respectively).

There were two patients with systemic thromboembolic events, both of who received $50 \mathrm{mg}$ dabigatran twice daily (1.96\%). One patient had a peripheral embolism to the toe, and the other patient had a stroke and a renal infarction. Seven patients reported angina, of which two patients were classified as having ACS: 1 treated with $50 \mathrm{mg}$ dabigatran twice daily plus $81 \mathrm{mg}$ ASA and the other treated with $300 \mathrm{mg}$ dabigatran twice daily plus $81 \mathrm{mg}$ ASA. Both patients were discontinued from the trial. Four patients developed congestive heart failure, with 1 patient receiving $150 \mathrm{mg}$ dabigatran twice daily discontinuing the trial. None of these events resulted in statistically significant differences between treatment groups.

There was a $0.9 \%$ incidence of increased aminotransferase levels $>3$ times the ULN of normal in dabigatran-treated patients (4 of 432). Adverse events were more frequent in the dabigatran groups than in the warfarin-treated patients. Because of liver function abnormalities associated with ximelagatran, the study had an extensive surveillance of liver function. Only $0.9 \%$ of patients had increased levels of ALT or AST $>3$ times the ULN. No patient had a drug-related increase in bilirubin $>2$ times the ULN within 30 days after an aminotransferase level increase $>3$ times the ULN. However, the duration of the study was only 12 weeks. ${ }^{43}$ The phase II clinical trial investigating dabigatran etexilate in patients with chronic $\mathrm{AF}$ is extended for 2 years to investigate the safety and efficacy of $\sim 360$ patients that have previously been treated in the Pedro study (see www.ClinicalTrials.gov; identifier NCT00157248, Pedro-Ex).

In a phase III trial, a randomized evaluation of long-term anticoagulant therapy (RE-LY) compares the efficacy and safety of two blinded doses of dabigatran etexilate with open-label warfarin for the prevention of stroke and systemic embolism in patients with nonvalvular AF. It is a prospective, multicenter, randomized, open-label, controlled parallel group, noninferiority trial. The primary end point is to demonstrate that the efficacy and safety of two blinded doses of dabigatran etexilate in patients with non-valvular $\mathrm{AF}$ are noninferior to warfarin treatment for the prevention of stroke and systemic embolism. Secondary outcome measures are the incidence of stroke (including hemorrhagic), systemic embolism, all death incidence of stroke (including hemorrhagic), systemic embolism, PE, acute MI, or vascular deaths (including deaths from bleeding). More than 15,000 patients will be randomized from $\sim 1000$ clinical sites within 44 countries. Patients will be randomized over a 2-year period with a minimum 1 year of follow-up and a maximum of 3 years and a mean of 1.5 years of follow-up (see www.ClinicalTrials. gov; identifier NCT00262600).

The currently available and ongoing clinical trials in patients for treatment of acute VTE, AF, and other medical indications are summarized in Table 7.

\section{CONCLUSION}

The future prospects of the new anticoagulants are based on the continuously improving trial designs. The potential advantages result in the possibility to administer the new anticoagulants to patients who have limitations for use of the conventional anticoagulants. The synthetic, 


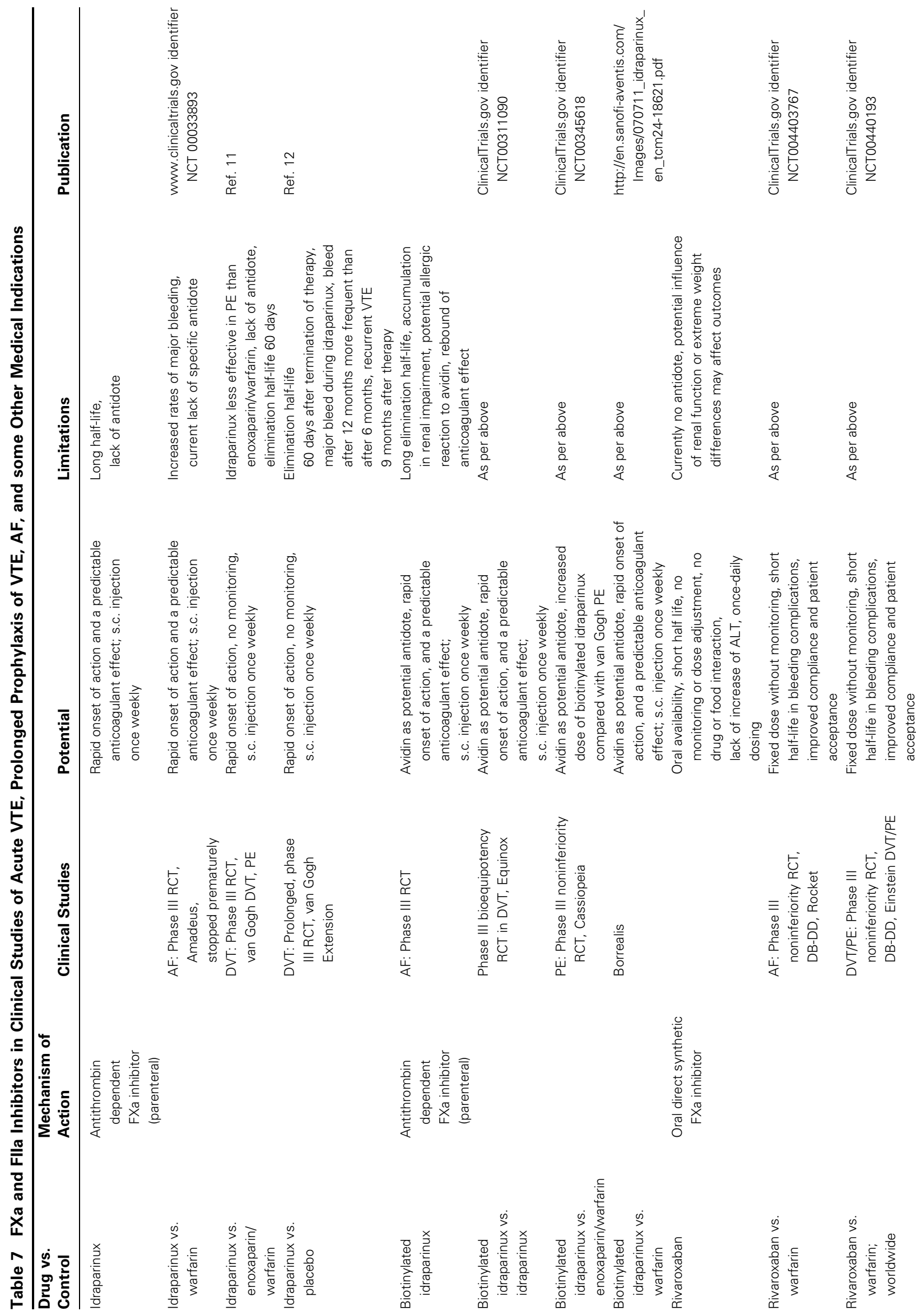



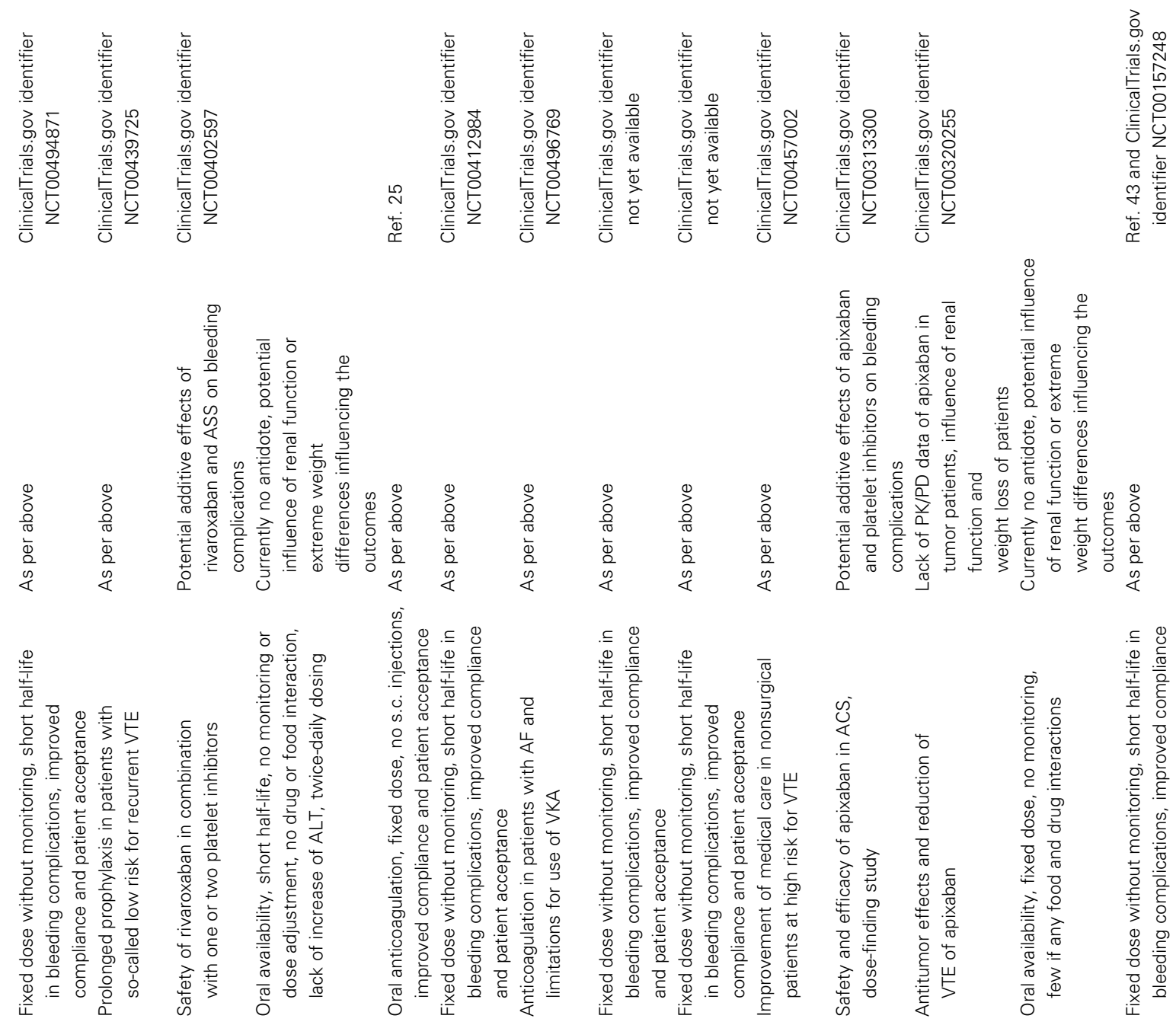

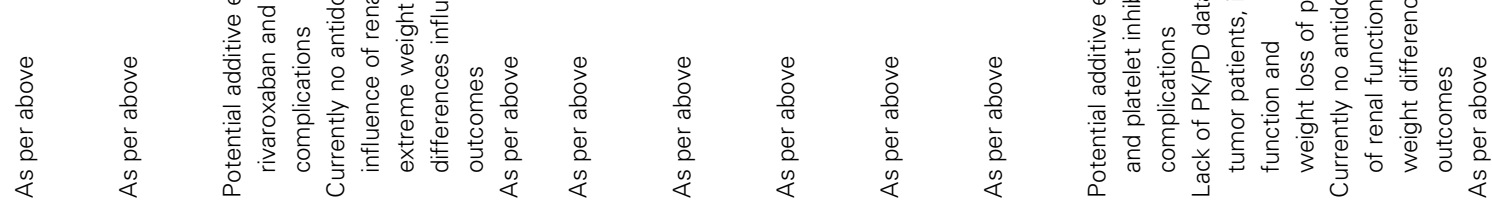
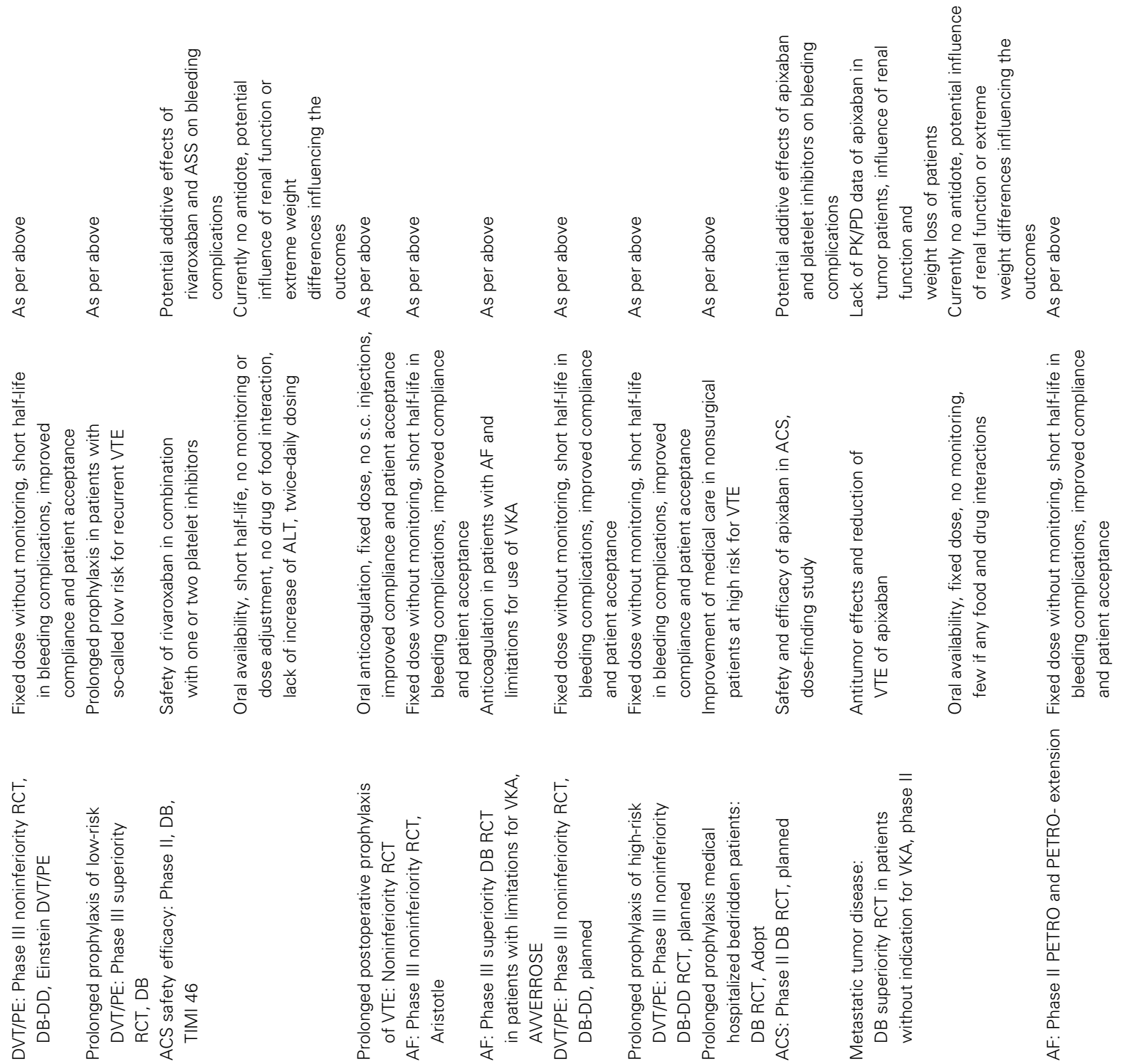

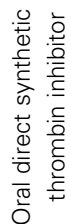

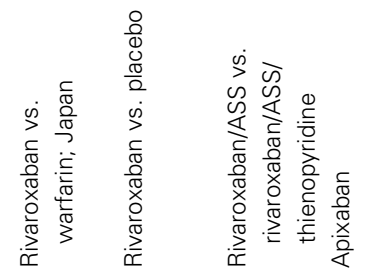

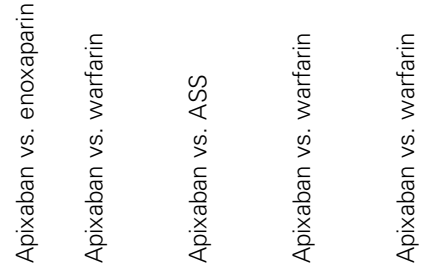

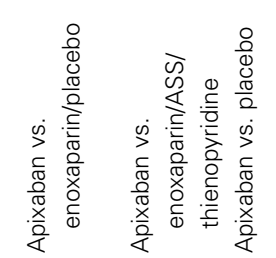

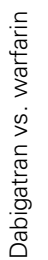




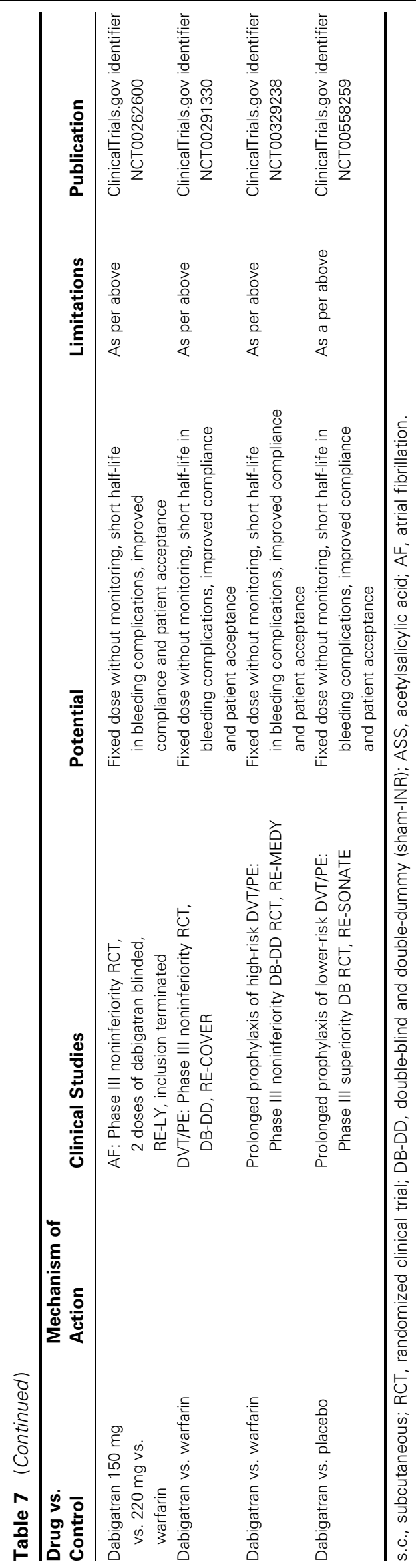

specific small molecules open the possibility to treat patients without monitoring and dose adjustment and to increase the safety. Dose-ranging studies demonstrated a broader therapeutic range compared with heparins and VKAs without increasing bleeding events. Prolonged treatment, therapy in elderly patients, new indications in cancer and immunologic disease, and combination with platelet inhibitors are indications and improvements of the new anticoagulants.

The question of advantages of oral direct FXa inhibitors and oral direct FIIa inhibitors may remain open for a long time. First, differences between each group of inhibitors with regard to efficacy and safety in an arterial and venous indication for prevention of thromboembolism in patients must be determined. In a second step, a head-to-head comparison of an oral direct FXa inhibitor and an oral direct thrombin inhibitor has to be performed if the advantage of one over the other class of new oral anticoagulants is intended to be proved. This decision can only be made upon the availability of published clinical trials in the same indications. However, it should be taken into consideration that in head-to-head comparisons of similar anticoagulants, the LMWHs, the hypothesis of clinically relevant differences has had to be rejected thus far in patients treated for acute VTE.

\section{REFERENCES}

1. Hirsh J, O'Donnell M, Eikelboom JW. Beyond unfractionated heparin and warfarin: current and future advances. Circulation 2007;116:552-560

2. Bates SM, Weitz JI. The status of new anticoagulants. Br J Haematol 2006;134:3-19

3. Eikelboom JW, Weitz JI. A replacement for warfarin: the search continues. Circulation 2007;116:131-133

4. Saiah E, Soares C. Small molecule coagulation cascade inhibitors in the clinic. Curr Top Med Chem 2005;5:1677-1695

5. Bauer KA. New anticoagulants. Hematology Am Soc Hematol Educ Program 2006:450-456

6. Turpie AGG. Oral, direct factor Xa inhibitors in development for the prevention and treatment of thromboembolic diseases. Arterioscler Thromb Vasc Biol 2007;27:1238-1247

7. $\mathrm{Ma} \mathrm{Q}_{2}$ Fareed J. Idraparinux sodium. Sanofi-Aventis. IDrugs 2004;7:1028-1034

8. Herbert JM, Herault JP, Bernat A, et al. Biochemical and pharmacological properties of SANORG 34006, a potent and long-acting pentasaccharide. Blood 1998;91:4197-4205

9. Bijsterveld NR, Vink R, Van Arken BE, et al. Recombinant factor VIIa reverses the anticoagulant effect of the longacting pentasaccharide idraparinux in healthy volunteers. Br J Haematol 2004;124:653-658

10. The PERSIST Investigators. A novel long-acting synthetic factor $\mathrm{Xa}$ inhibitor (SanOrg34006) to replace warfarin for secondary prevention in deep vein thrombosis: a phase II evaluation. J Thromb Haemost 2004;2:47-53

11. The van Gogh Investigators. Idraparinux versus standard therapy for venous thromboembolic disease. N Engl J Med 2007;357:1094-1104 
12. The van Gogh Investigators. Extended prophylaxis of venous thromboembolism with idraparinux. N Engl J Med 2007; 357:1105-1112

13. Harenberg J, Joerg I, Hagedorn A, Giese C, Mikus G, Weiss C. Anticoagulant effects of idraparinux after termination of therapy for prevention of recurrent venous thromboembolism: observations after the vanGogh Trials. Eur J Clin Pharmacol 2008; in press

14. Savi P, Herault JP, Duchaussoy P, et al. Reversible biotinylated oligosaccharides, a new approch for a better management of the anticoagulant therapy. J Thromb Haemost Suppl 2007; abstract P-W-645

15. Harenberg J, Joerg I, Hagedorn A, Giese C. Bleeding and thromboembolic events after termination of therapy with idraparinux for prevention of recurrent venous thromboembolism-observation after the van Gogh Trials. Blood 2007; 110:abstract 1877

16. Rezaie AR. DX-9065a inhibition of factor Xa and the prothrombinase complex: mechanism of inhibition and comparison with therapeutic heparins. Thromb Haemost 2003;89:112-121

17. Dyke CK, Becker RC, Kleiman NS, et al. First experience with direct factor $\mathrm{Xa}$ inhibition in patients with stable coronary disease: a pharmacokinetic and pharmacodynamic evaluation. Circulation 2002;105:2385-2391

18. Alexander JH, Yang $\mathrm{H}$, Becker RCet alon behalf of the XANADU-ACS Investigators. First experience with direct, selective factor $\mathrm{Xa}$ inhibition in patients with non-STelevation acute coronary syndromes: results of the XANADU-ACS trial. J Thromb Haemost 2005;3:439-447

19. Ansell J. Factor Xa or thrombin: is factor $\mathrm{Xa}$ a better target? J Thromb Haemost 2007;5(Suppl 1):60-64

20. Kubitza D, Haas S. Novel factor Xa inhibitors for prevention and treatment of thromboembolic diseases. Expert Opin Investig Drugs 2006;15:843-855

21. Eriksson BI, Lars C, Borris LC, et al, for the ODIXa-HIP Study Investigators.. A once-daily, oral, direct factor $\mathrm{Xa}$ inhibitor, rivaroxaban (BAY 59-7939), for thromboprophylaxis after total hip replacement. Circulation 2006;114:23742381

22. Agnelli G, Gallus A, Goldhaber SZ, et al, for the ODIXaDVT Study Investigators.. Treatment of proximal deep-vein thrombosis with the oral direct factor $\mathrm{Xa}$ inhibitor rivaroxaban (BAY 59-7939) The ODIXa-DVT Study. Circulation 2007;116:180-187

23. Buller HR. Once-daily treatment with an oral, direct factor Xa inhibitor- rivaroxaban (BAY 59-7939)-in patients with acute, symptomatic deep vein thrombosis: the EINSTEINDVT dose-finding study [abstract]. Eur Heart J 2006; 27(Suppl):761

24. Pinto DJ, Orwat MJ, Koch S, et al. Discovery of 1-(4methoxyphenyl)-7-oxo-6-(4-(2-oxopiperidin-1-yl)phenyl)4,5,6,7-tetrahydro-1H-pyrazolo[3,4-c]pyridine-3-carboxamide (apixaban, BMS-562247), a highly potent, selective, efficacious, and orally bioavailable inhibitor of blood coagulation factor Xa. J Med Chem 2007;50:5339-5356

25. Lassen MR, Davidson BL, Gallus A, Pineo G, Ansell J, Deitchman D. The efficacy and safety of apixaban, an oral, direct factor $\mathrm{Xa}$ inhibitor, as thromboprophylaxis in patients following total knee replacement. J Thromb Haemost 2007; 5:2368-2375

26. Buller HR. A dose finding study of the oral direct factor $\mathrm{Xa}$ inhibitor apixaban in the treatment of patients with acute symptomatic deep vein thrombosis-The Botticelli Investigators. J Thromb Haemost 2007;5(Suppl):abstract O-S-003

27. Norman P. Medicinal Chemistry-12th RSC-SCI Symposium (Part I), Enzyme Inhibitors. Cambridge, UK: IDdb Meeting Report; 2003

28. Agnelli G, Haas SK, Krueger KA, Ginsberg JS, Dmitrienko A, Brandt JT. A phase II study of the safety and efficacy of a novel oral $\mathrm{fXa}$ inhibitor (LY517717) for the prevention of venous thromboembolism following TKR or THR. J Thromb Haemost 2007;5:746-753

29. Iwatsuki Y, Shigenaga T, Moritani Y, et al. Biochemical and pharmacological profiles of YM150, an oral direct factor Xa inhibitor. Blood 2006;108:abstract 911

30. Eriksson BI, Turpie AGG, Lassen MRet alfor the Onyx Study Group. A dose escalation study of YM150, an oral direct factor $\mathrm{Xa}$ inhibitor, in the prevention of venous thromboembolism in elective primary hip replacement surgery. J Thromb Haemost 2007;5:1660-1665

31. Zafar MU, Vorchheimer DA, Gaztanaga J, et al. Antithrombotic effects of factor $\mathrm{Xa}$ inhibition with DU-176b: phase-I study of an oral, direct factor Xa inhibitor using an ex-vivo flow chamber. Thromb Haemost 2007;98:883-888

32. Linkins LA, Weitz JI. Pharmacology and clinical potential of direct thrombin inhibitors. Curr Pharm Des 2005;11:38773884

33. Weitz JI. Factor Xa or thrombin: is thrombin a better target? J Thromb Haemost 2007;5(Suppl 1):65-67

34. Weitz JI, Buller HR. Direct thrombin inhibitors in acute coronary syndromes: present and future. Circulation 2002; 105:1004-1011

35. Gustafsson D, Nystrom J, Carlsson S, et al. The direct thrombin inhibitor melagatran and its oral prodrug H376/95: intestinal absorption properties, biochemical and pharmacodynamic effects. Thromb Res 2001;101:171-181

36. Wolzt M, Sarich TS, Eriksson UG. Pharmacokinetics and pharmacodynamics of ximelagatran. Semin Vasc Med 2005; 5:245-253

37. Harenberg J, Jörg I, Weiss C. Observations of alanine aminotransferase and aspratate aminotransferase in THRIVE studies treated orally with ximelagatran. Int J Toxicol 2006; 25:165-169

38. Harenberg J, Jörg I, Weiss C. Incidence of recurrent venous thromboembolism of patients after termination of treatment with ximelagatran. Eur J Clin Pharmacol 2006;62:173-177

39. Lee WM, Larrey D, Olsson R, et al. Hepatic findings in longterm clinical trials of ximelagatran. Drug Saf 2005;28:351-370

40. Gurewich V. Ximelagatran-promises and concerns. JAMA 2005;293:736-739

41. Stangier KJ, Rathgen K, Staehle H, Gansser D, Roth W. The pharmacokinetics, pharmacodynamics and tolerability of dabigatran etexilate, a new oral direct thrombin inhibitor, in healthy male subjects. Br J Clin Pharmacol 2007;64:292303

42. Eriksson BI, Dahl OE, Buller HR, et al. A new oral direct thrombin inhibitor, dabigatran etexilate, compared with enoxaparin for prevention of thromboembolic events following total hip or knee replacement: the BISTRO II randomized trial. J Thromb Haemost 2005;3:103-111

43. Ezekowitz MD, Reilly PA, Nehmiz G, et al. Dabigatran with or without concomitant aspirin compared with warfarin alone in patients with nonvalvular atrial fibrillation (PETRO Study). Am J Cardiol 2007;100:1419-1426 